\section{A variant erythroferrone disrupts iron homeostasis in SF3B1-mutated myelodysplastic syndrome}

\author{
Sabrina Bondu ${ }^{1,2,3,4 *}$, Anne-Sophie Alary ${ }^{1,2,3,4,5 *}$, Carine Lefèvre ${ }^{1,2,3,4,6}$, Alexandre Houy ${ }^{7}$, \\ Grace Jung $^{8}$, Thibaud Lefebvre ${ }^{1,6,9}$, David Rombaut 1,2,3,4 , Ismael Boussaid 1,2,3,4, \\ Abderrahmane Bousta ${ }^{1,2,3,4}$, François Guillonneau ${ }^{1,2,3,4,10}$, Prunelle Perrier $^{11}$, Samar Alsafadi ${ }^{12}$, \\ Michel Wassef $^{13}$, Raphaël Margueron ${ }^{13}$, Alice Rousseau ${ }^{1,2,3,4}$, Nathalie Droin ${ }^{14}$, Nicolas Cagnard ${ }^{1,15}$, \\ Sophie Kaltenbach ${ }^{1,16}$, Susann Winter ${ }^{17}$, Anne-Sophie Kubasch ${ }^{18}$, Didier Bouscary ${ }^{1,2,3,4,19}$, \\ Valeria Santini ${ }^{20}$, Andrea Toma ${ }^{21}$, Mathilde Hunault ${ }^{22}$, Aspasia Stamatoullas ${ }^{23}$, Emmanuel Gyan ${ }^{24}$, \\ Thomas Cluzeau $^{25}$, Uwe Platzbecker ${ }^{18}$, Lionel Adès ${ }^{1,26}$, Hervé Puy ${ }^{1,6,9}$, Marc-Henri Stern ${ }^{27}$, \\ Zoubida Karim ${ }^{1,6,9}$, Patrick Mayeux ${ }^{1,2,3,4,6,10}$, Elizabeta Nemeth ${ }^{8}$, Sophie Park ${ }^{28}$, Tomas Ganz ${ }^{8}$, \\ Léon Kautz $^{11}$, Olivier Kosmider ${ }^{1,2,3,4,5,6 \dagger}$, Michaëla Fontenay ${ }^{1,2,3,4,5,6 \dagger}$
}

Myelodysplastic syndromes (MDS) with ring sideroblasts are hematopoietic stem cell disorders with erythroid dysplasia and mutations in the SF3B1 splicing factor gene. Patients with MDS with SF3B1 mutations often accumulate excessive tissue iron, even in the absence of transfusions, but the mechanisms that are responsible for their parenchymal iron overload are unknown. Body iron content, tissue distribution, and the supply of iron for erythropoiesis are controlled by the hormone hepcidin, which is regulated by erythroblasts through secretion of the erythroid hormone erythroferrone (ERFE). Here, we identified an alternative ERFE transcript in patients with MDS with the SF3B1 mutation. Induction of this ERFE transcript in primary SF3B1-mutated bone marrow erythroblasts generated a variant protein that maintained the capacity to suppress hepcidin transcription. Plasma concentrations of ERFE were higher in patients with MDS with an SF3B1 gene mutation than in patients with SF3B1 wild-type MDS. Thus, hepcidin suppression by a variant ERFE is likely responsible for the increased iron loading in patients with SF3B1-mutated MDS, suggesting that ERFE could be targeted to prevent iron-mediated toxicity. The expression of the variant ERFE transcript that was restricted to SF3B1-mutated erythroblasts decreased in lenalidomideresponsive anemic patients, identifying variant ERFE as a specific biomarker of clonal erythropoiesis.
Copyright @ 2019 The Authors, some rights reserved; exclusive licensee American Association for the Advancement of Science. No claim to original U.S. Government Works

\section{INTRODUCTION}

Myelodysplastic syndromes with ring sideroblasts (MDS-RS) are clonal hematopoietic stem cell (HSC) disorders with a prominent erythroid dysplasia of the bone marrow (BM) responsible for a macrocytic anemia. Mitochondrial iron accumulation and apoptosis of mature erythroblasts cause ineffective erythropoiesis $(1,2)$. In contrast to other MDS subtypes, patients with MDS-RS exhibit signs of systemic iron accumulation that is reflected by increased ferritin and nontransferrin bound iron concentrations even before they become transfusion dependent and subsequently develop parenchymal iron overload $(3,4)$.
Splicing factor gene SF3B1 is mutated in $~ 90 \%$ of MDS-RS, and the diagnosis is considered whenever the gene is mutated, although the percentage of RS is relatively low, between 5 and 15\% (5-7). These mutations arise in the HSCs $(8-10)$. Aberrant splicing events are reported in MDS and other SF3B1-driven cancers, including uveal melanoma and chronic lymphocytic leukemia (CLL) (11-14). The selection of an alternative branch site resulting in the use of a cryptic $3^{\prime}$ splice site (ss) is the most frequently detected abnormality. Computational analysis revealed that most of the cryptic 3 'ss are located upstream of canonical 3 'ss at nucleotide distances that are not multiples of 3 , suggesting that the aberrant transcripts would

\footnotetext{
'Université de Paris, Paris 75006, France. ${ }^{2}$ Institut Cochin, Département Développement, Reproduction, Cancer, Paris 75014, France. ${ }^{3}$ Institut National de la Santé et de la Recherche médicale (INSERM) U1016, Paris 75014, France. ${ }^{4}$ Centre National de la Recherche Scientifique (CNRS) Unité Mixte de recherche (UMR) 8104, Paris 75014, France. ${ }^{5}$ Service d'hématologie biologique, Assistance Publique-Hôpitaux de Paris (AP-HP), Hôpitaux Universitaires Paris Centre-Cochin, Paris 75014 , France. ${ }^{6}$ Laboratoire d'excellence du Globule Rouge GR-Ex, Paris 75015, France. Institut Curie, PSL Research University, Human Genetics and Oncogenesis, Paris 75005, France. ${ }^{8}$ Department of Medicine, David Geffen School of Medicine, University of California, Los Angeles, CA 90095, USA. ${ }^{9}$ INSERM, UMR 1149/ERL CNRS 8252, Centre de Recherches sur l'inflammation, Université de Paris, Paris 75018, France. ${ }^{10}$ Proteomic platform 3P5, Université de Paris, Paris 75014, France. ${ }^{11}$ Institut de Recherche en Santé Digestive (IRSD), Université de Toulouse, INSERM U1220, Institut National de la Recherche Agronomique U1416, Ecole Nationale Vétérinaire de Toulouse, Université Paul Sabatier, Toulouse 31024, France. ${ }^{12}$ Institut Curie, PSL Research University, Department of Translational Research, Paris 75005, France. ${ }^{13}$ Institut Curie, PSL Research University, INSERM 934/UMR 3215, Genetics and biology of Development, Paris 75005 France. ${ }^{14}$ Institut Gustave Roussy, Genomic platform, Villejuif 94805 , France. ${ }^{15}$ Platform Bioinformatics, Université de Paris, Paris 75015, France. ${ }^{16}$ Laboratoire de Génétique, AP-HP, Hôpital Necker, Paris 75015, France. ${ }^{17}$ Medical Clinic und Policlinic 1, Technische Universität Dresden, Dresden 01307, Germany. ${ }^{18}$ Medical Clinic und Policlinic 1, Hematology and Cellular Therapy, University Hospital, Leipzig 04103, Germany. ${ }^{19}$ Service d'Hématologie clinique, AP-HP, Hôpitaux Universitaires Paris Centre-Cochin, Paris 75014, France. ${ }^{20}$ MDS unit, Hematology, AOU Careggi, University of Florence, Florence 50134, Italy. ${ }^{21}$ Département d'Hématologie, AP-HP, Hôpital Henri-Mondor, Université Paris 12, Créteil 94000, France. ${ }^{22}$ Service des Maladies du Sang, Centre hospitalo-universitaire, Angers 49100 , France. ${ }^{23}$ Département d'hématologie, Centre Henri-Becquerel, Rouen 76038, France. ${ }^{24}$ Service d'hématologie et thérapie cellulaire, Centre hospitalo-universitaire, CNRS ERL 7001 LNOx, Université de Tours, Tours 37044, France. ${ }^{25}$ Côte d'Azur University, CHU of Nice, Hematology department and INSERM U1065, Mediterranean Center of Molecular Medecine, Nice 06204, France. ${ }^{26}$ Service d'Hématologie Senior, AP-HP, Hôpital Saint-Louis, Paris 75010, France. ${ }^{27}$ Institut Curie, PSL Research University, INSERM U830, Genetics and biology of cancers, DNA repair and uveal melanoma (D.R.U.M.), Équipe labellisée par la Ligue nationale contre le cancer, Paris 75005 , France. ${ }^{28}$ Département d'Hématologie, Centre Hospitalier Universitaire, Université de Grenoble Alpes, La Tronche 38700, France.

*These authors contributed equally to this work.
}

tCorresponding author. Email: michaela.fontenay@inserm.fr (M.F.); olivier.kosmider@aphp.fr (O.K.) 
likely contain a premature termination codon (PTC) and be degraded by nonsense-mediated decay (NMD). It has been predicted that half of the aberrantly spliced transcripts in SF3B1-mutated cells are NMD sensitive and that the canonical isoforms are down-regulated (11). For instance, $A B C B 7$ transcript encoding a mitochondrial transporter involved in the export of $\mathrm{Fe}$-S clusters is aberrantly spliced and undergoes NMD. It is also possible that NMD-insensitive aberrant transcripts are translated into proteins with altered function (11). Globally, missplicing may contribute to defective messenger RNA (mRNA) production and deregulation of cellular pathways $(15,16)$. How these aberrant splicing events contribute to the disease phenotype and in particular to systemic iron overload is unclear.

In contrast with other MDS subtypes, MDS-RS are associated with lower expression of the iron homeostasis regulator, hepcidin, and as a consequence, the absorption of iron by duodenal enterocytes and its release from erythrophagocytic macrophages may be increased (17-22). Inappropriately low hepcidin concentrations in MDS-RS could depend on the degree of ineffective erythropoiesis linked to impaired iron incorporation into heme because of mitochondrial iron trapping and/or to increased expression of hepcidin repressors (23). Growth differentiation factor 15 (GDF-15) and twisted gastrulation (TWSG1), two members of the transforming growth factor- $\beta$ superfamily, have been proposed as pathological suppressors of hepcidin in ineffective erythropoiesis $(24,25)$. More recently, erythroferrone (ERFE), a C1q-tumor necrosis factor-related family of proteins (CTRP) member, has been described as a major erythroid regulator of hepcidin, involved in the pathological suppression of hepcidin in patients with $\beta$-thalassemia $(26,27)$.

In the present study, we identify a variant transcript of ERFE specific to SF3B1-mutated MDS. The expression of the variant $E R F E$ is restricted to the erythroid lineage, and the variant contributes to increased concentration of ERFE protein, resulting in hepcidin suppression and systemic iron accumulation in patients. This variant appears to be a pertinent biomarker of clonal erythropoiesis with potential use for monitoring treatment response of anemic patients with SF3B1-mutated MDS.

\section{RESULTS \\ Up-regulation of ERFE using an alternative 3'ss in SF3B1-mutated MDS}

To investigate the mechanism of systemic iron overload, we established a cohort of 156 patients with lower-risk MDS, including 60 MDS-RS with single lineage dysplasia (SLD), 17 MDS-RS with multilineage dysplasia (MLD), 2 5q-syndrome, 17 MDS-SLD, 42 MDS-MLD, and 18 MDS with type 1 excess of blasts (EB1) (table S1). The Revised International Prognostic Scoring System score was very low in 15, low in 95, intermediate in 36 , and high in 4 patients. Twenty-six genes commonly mutated in MDS were sequenced in the BM mononuclear cell (MNC) fraction. The SF3B1 gene was mutated in 94 patients with MDS, including $63(67 \%)$ affected by an $S F 3 B 1^{\mathrm{K} 700 \mathrm{E}}$ mutation. Among the 62 patients with no SF3B1 mutation, other splicing genes, SRSF2, U2AF1, or ZRSR2, were mutated in 27 cases, and no splicing gene mutation was observed in 35 cases. Some patients presented with two splicing mutations (fig. S1). We evaluated the consequences of $S F 3 B 1$ gene mutations on gene expression and splicing by sequencing the transcriptome of the BM MNCs isolated from 27 patients in this cohort, including 21 with $S F 3 B 1^{\mathrm{MUT}}$ MDS, 6 with SF3B1 ${ }^{\text {WT }}$ MDS, and 5 healthy controls. Differential analyses of gene expression and splice junctions were conducted using DESeq2 (28). We detected 6343 genes as differentially expressed between SF3B1 ${ }^{\text {MUT }}$ MDS and SF3B1 $1^{\text {WT }}$ MDS with $P<0.05$ (data file S1). Principal components analysis of gene expression profiles separated $S F 3 B 1^{\mathrm{MUT}}$ and $S F 3 B 1^{\mathrm{WT}}$ MDS (Fig. 1A). The differentially expressed genes were enriched in 73 specific gene ontology (GO) terms with an absolute $\log _{2}$ fold change $(\mathrm{FC})>1$ and a Benjamini-Hochberg $(\mathrm{BH})$-adjusted $P$ value $<0.05$ (Fig. 1B). Genes with $\log _{2}(\mathrm{FC})<-1$ were involved in serine/threonine kinase signaling, apoptosis, myeloid differentiation, inflammation, and cell-cell adhesion, whereas those with a $\log _{2}(\mathrm{FC})>1$ were involved in heme metabolism, erythrocyte differentiation, and iron homeostasis (Fig. 1C). We plotted the $\log _{2}$ (FC) of 16 differentially expressed genes belonging to the IRON_ION_HOMEOSTASIS gene set (GO:0055072; http://amigo. geneontology.org) and showed that the FAM132B/ERFE transcript encoding ERFE was increased (Fig. 1D). The FAM132B/ERFE transcript was similarly expressed in samples with an epigenetic TET2 ${ }^{\mathrm{MUT}}$ / $D N M T 3 A^{\mathrm{WT}} / S F 3 B 1^{\mathrm{WT}}$ genotype compared to healthy controls or with a DNMT3A $A^{\mathrm{MUT}} / T E T 2^{\mathrm{WT}} / S F 3 B 1^{\mathrm{MUT}}$ compared to DNMT3A ${ }^{\mathrm{WT}} /$ $T E T 2^{\mathrm{WT}} / S F 3 B 1^{\mathrm{MUT}}$ genotype, suggesting that the deregulation of ERFE transcript expression was linked to SF3B1 mutation (table S2).

We then identified 1528 differentially expressed $5^{\prime}$ and $3^{\prime}$ junctions, including annotated $5^{\prime}$ donor and $3^{\prime}$ acceptor ss, ambiguous junctions, and canonical junctions with $\mathrm{BH}$-adjusted $P$ values $\leq 10^{-5}$ and absolute $\log _{2}(\mathrm{FC}) \geq 1$ (data file S2). These junctions allowed the hierarchical clustering of the $21 S F 3 B 1^{\mathrm{MUT}}$ and $6 S F 3 B 1^{\mathrm{WT}}$ MDS samples (Fig. 2A). After excluding differentially expressed canonical junctions, we then considered the 1147 alternative junctions, among which we identified $7863^{\prime}$ acceptor junctions (68.5\%), $1765^{\prime}$ donor junctions (15.3\%), and 185 ambiguous junctions (16.1\%) attributed to either the alternative $5^{\prime}$ or $3^{\prime}$ ss or both alternative $5^{\prime}$ and $3^{\prime}$ ss (Fig. 2B). The analysis of distances between the alternative and canonical 3'ss showed that most of the alternative 3 'ss $\left(\mathrm{AG}^{\prime}\right)$ were located between -24 and -9 nucleotides $(n t)$ preceding the canonical 3 'ss (AG) (Fig. 2C). The proportion of alternative $\mathrm{AG}^{\prime}$ junctions in these novel splice variants generally increased in $S F 3 B 1$ mutants and less frequently in $S F 3 B 1^{\text {WT }}$ samples (Fig. 2D). To detect alternative transcripts that were likely to generate substantial amounts of variant proteins with a modified length, we applied a filter selecting transcripts with an additional stretch of nucleotides numbering in multiples of 3 , a ratio of alternative junction coverage $\left(\mathrm{AG}^{\prime}\right)$ to alternative and canonical junctions coverage $\left(\mathrm{AG}^{\prime}+\mathrm{AG}\right)$ of more than 0.1 , and an expression ratio of the alternative junction in $S F 3 B 1^{\text {MUT }}$ versus $S F 3 B 1^{\text {WT }}$ samples of more than 10 (fig. S2A). We obtained 66 alternative junctions in 63 genes (data file S3 and fig. S2B). These genes were involved in epigenetic regulation and transcription, mRNA processing and translation, intracellular transport, cell cycle and migration, signaling and apoptosis, mitochondrial metabolism, and iron homeostasis (Fig. 2E). Among the 66 alternative junctions, 29 were related to an in-frame insertion of 9 to $27 \mathrm{nt}$, and 26 of them were differentially expressed between $S F 3 B 1^{\mathrm{MUT}}$ and $S F 3 B 1^{\mathrm{WT}}$ MDS with an absolute $\log _{2}(\mathrm{FC})>0.3$ (Fig. 2F). The FAM132B/ERFE gene was identified among the up-regulated genes with an alternative junction due to the use of a cryptic 3'ss located between exons 2 and 3 (chr2: $239,070,357$ to $239,071,364$ ) and no PTC. The aberrant transcript contained 12 additional nucleotides in the open reading frame and from here on is referred to as $E R F E^{+12}$ (Fig. 2G). It was systematically detected in all SF3B1 ${ }^{\mathrm{MUT}}$ MDS samples and represented a mean percentage of $24.8 \%$ of FAM132B/ERFE transcripts in SF3B1 ${ }^{\mathrm{MUT}}$ MDS versus 


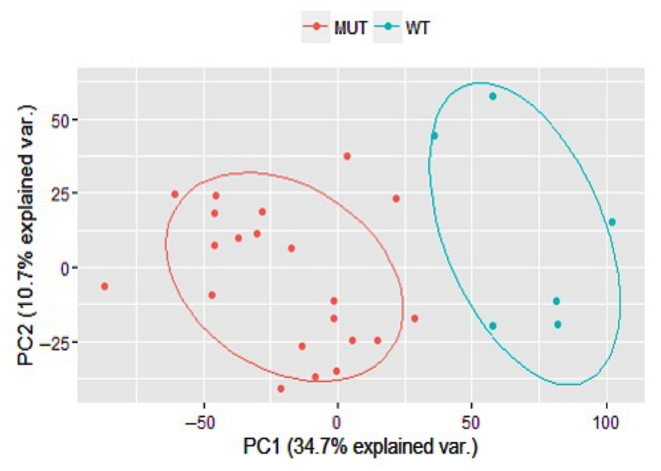

C
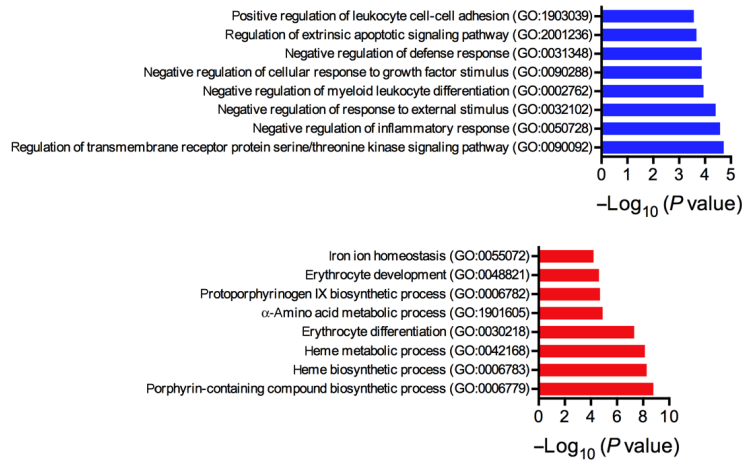

Fig. 1. Differential gene expression in SF3B1 ${ }^{\text {MUT }}$ MDSs. (A) Biplot of the first two principal components (PCs) showing $45.4 \%$ of the variability within the data (PC1, $x$ axis; $P C 2, y$ axis). (B) Volcano plot showing differentially expressed transcripts in SF3B $1^{\text {MUT }}$ BM MNCs compared to SF3B $1^{\text {WT }}$ BM MNCs. Fold change (FC) on the $x$ axis and negative log ${ }_{10}$ of Benjamini-Hochberg $(\mathrm{BH})$ corrected $P$ values on the $y$ axis. Dotted vertical and horizontal lines reflect the filtering criteria (FC $<0.5$ or $>2.0$; and $\mathrm{BH}$-corrected $P$ value $<0.05$ ). The red dots represent differentially up-regulated transcripts, the blue dots represent differentially down-regulated transcripts, and the gray dots represent transcripts without differential expression. (C) GO enrichment analysis of differentially expressed genes with an absolute $\log _{2}(\mathrm{FC})>1$ and a $P$ value $<$ 0.05 in SF3B $1^{\text {MUT }}$ MDS. The most down-regulated and up-regulated gene sets are represented. (D) $\log _{2}(F C)$ of the expression of 16 among the 96 genes of the IRON_ION_HOMEOSTASIS gene set (GO:005072) deregulated in SF3B $1^{\text {MUT }}$ MDS. we performed a minigene splicing assay. An ERFE sequence of about $200 \mathrm{nt}$ located on both sides of the cryptic 3'ss $\left(\mathrm{AG}^{\prime}\right)$ was cloned in an Exontrap vector. The alternative junction in ENOSF1 gene (chr18: 683,395 to 685,920 ) cloned in the same vector was used as a control (13). These minigenes were transfected into the murine G1E-ER4 cell line in which the $S F 3 B 1^{\mathrm{K} 700 \mathrm{E}}$ mutation was edited by CRISPR-Cas9 technology. As expected due to the lack of intron homology between species, sequencing the transcriptome of G1E-ER4 $S F 3 B 1^{\mathrm{K} 700 \mathrm{E}}$ cell line or isogenic $S F 3 B 1^{\mathrm{WT}}$ cell line demonstrated that endogenous murine ERFE and ENOSF1 did not undergo alternative splicing (12). After transfection, the alternative $3^{\prime}$ ss $^{\prime} \mathrm{AG}^{\prime} E R F E^{+12}$ was detected by capillary electrophoresis in G1E-ER4 $S F 3 B 1^{\mathrm{K} 700 \mathrm{E}}$ cells but not in the isogenic G1E-ER4 SF3B $1^{\text {WT }}$ or parental cells (Fig. 3B). The usage of alternative 3 'ss $A G^{\prime}$ was detectable for ENOSF1 gene in the $S F 3 B 1^{\mathrm{WT}}$ cell line and became predominant in the $S F 3 B 1^{\mathrm{K} 700 \mathrm{E}}$ cell line, suggesting that the mutation favored the usage of alternative $\mathrm{AG}^{\prime}$. Then, we performed a rescue experiment by adding a destabilization domain (DD) tag to the mutant $S F 3 B 1^{\mathrm{R} 625 \mathrm{G}}$ allele in the Mel202 cell line, as previously described (29). The DD-tagged protein is stabilized by interaction with the DD ligand Shield- 1 and is degraded upon Shield- 1 withdrawal. In Mel202 clone 26 containing one DD-tagged $S F 3 B 1^{\mathrm{R} 625 \mathrm{G}}$ allele, Shield-1 removal abrogated $E R F E^{+12}$ expression. This supports a causal relationship between $S F 3 B 1$ mutation and the aberrant splicing isoform of ERFE (fig. S3).

We then investigated the expression of $0.2 \%$ in $S F 3 B 1^{\mathrm{WT}}$ MDS. The mutation pattern of samples expressing $E R F E^{+12}$ is shown in fig. S2C. This indicates that the expression of $E R F E^{+12}$ was strongly linked to the presence of a mutation in the SF3B1 gene.

\section{$S F 3 B 1^{M U T}$-restricted expression of alternative $E R E^{+12}$ transcript}

To ascertain that expression of the $E R F E^{+12}$ transcript is dependent on the presence of an SF3B1 mutation, we transfected the erythromegakaryocytic cell line UT7/erythropoietin (EPO) with a pLVX plasmid encoding a synthetic full-length $S F 3 B 1^{\mathrm{WT}}$ or mutant $S F 3 B 1^{\mathrm{K} 700 \mathrm{E}}$ complementary DNA (cDNA). We then designed a sensitive fluorescent polymerase chain reaction (PCR) allowing the detection of $E R F E^{+12}$ and $E R F E^{\mathrm{WT}}$ transcripts as 162 - and 150-nt fragments by capillary electrophoresis (table S3). Twenty-four hours after transfection, $E R F E^{+12}$ transcript was detected in $S F 3 B 1^{\mathrm{K} 700 \mathrm{E}}$-transfected cells but not in $S F 3 B 1^{\mathrm{WT}}$ cells (Fig. 3A). To validate the splice pattern induced in the context of $S F 3 B 1$ mutation in ERFE pre-mRNA,
$E R F E^{\mathrm{WT}}$ and $E R F E^{+12}$ in primary BM samples of patients with MDS using fluorescent PCR and real-time quantitative PCR (RT-qPCR) (table S3). Among 46 patients with lower-risk MDS, SF3B1 ${ }^{\mathrm{MUT}}$ was present in 25 patients, including 20 with MDS-SLD-RS/MDS-MLD-RS, 3 with MDS-MLD, and 2 with MDS-EB1. By fluorescent PCR, $E R F E^{+12}$ was detected in the BM MNC fractions of all $S F 3 B 1^{\text {MUT }}$ MDS. ERFE ${ }^{+12}$ was not detected in any other cases of MDS with mutations in SRSF2 $(n=10), \operatorname{UAFF} 1(n=1)$, or ZRSR2 $(n=1)$, or in 9 patients with MDS with mutations in other genes, as shown in Fig. $3 \mathrm{C}$ and table S4. ERFE $E^{\mathrm{WT}}$ and $E R F E^{+12}$ mRNA amounts measured by RT-qPCR were up-regulated in $S F 3 B 1^{\mathrm{MUT}}$ samples compared to any $S F 3 B 1^{\mathrm{WT}}$ samples with other splicing or epigenetic mutations or without recurrent mutation (Fig. 3D and table S4). In one patient with an SF3B1 monoallelic deletion and a G742D substitution on the remaining allele, the expression of alternative $E R F E^{+12}$ exceeded that of the canonical ERFE ${ }^{\mathrm{WT}}$ (fig. S4). We then amplified primary erythroblasts from the $\mathrm{BM} \mathrm{CD} 34^{+}$cells of two 


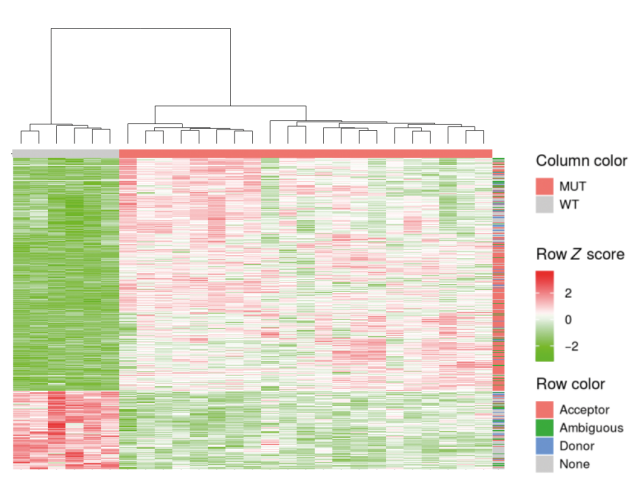

B

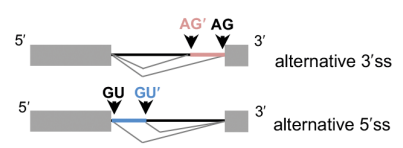

C

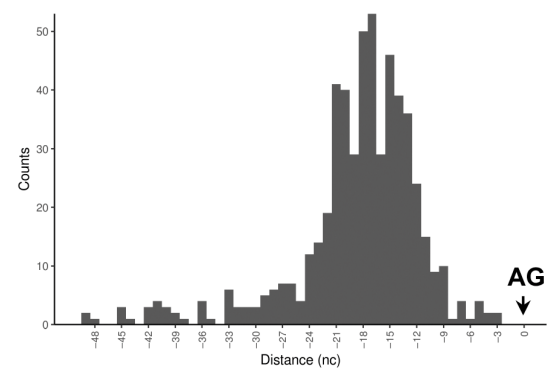

E

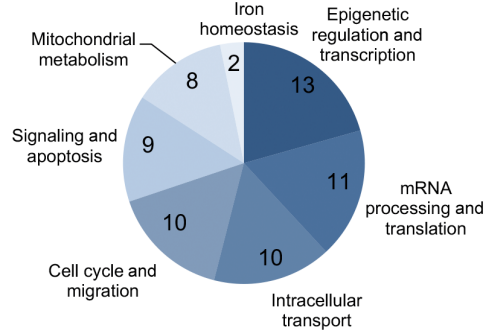

G

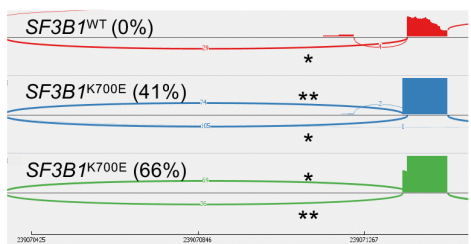

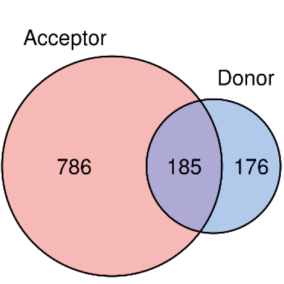

D

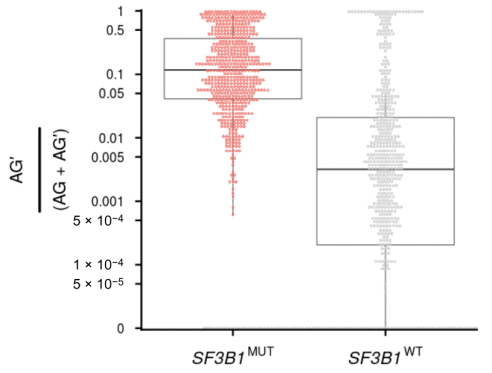

$\mathbf{F}$
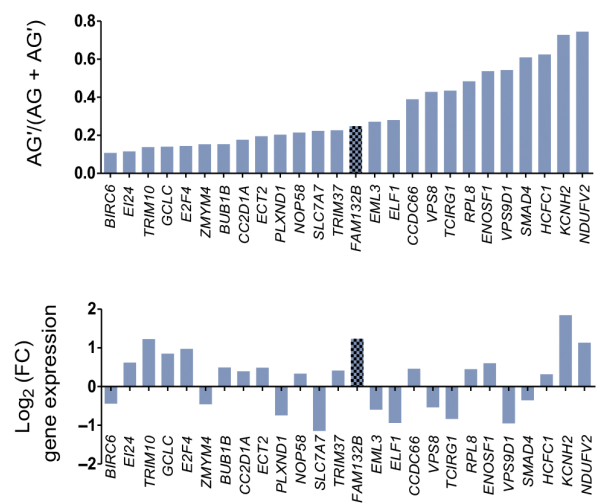

patients with $S F 3 B 1^{\mathrm{MUT}}$ and one patient with $S F 3 B 1^{\mathrm{WT}}$ MDS and showed that $E R F E^{+12}$ was expressed in $S F 3 B 1^{\mathrm{MUT}}$ but not in $S F 3 B 1^{\text {WT }}$ erythroid cells (Fig. 3E). This further supports the idea that $E R F E^{+12}$ is related to $S F 3 B 1$ mutation. $S F 3 B 1^{\mathrm{MUT}}$ MDS are characterized by the enrichment of the BM with erythroid cells. To investigate whether $E R F E^{+12}$ could be detected in cells derived from erythroblastic BM with another genetic background, we collected samples from one patient with MDS-RS with $38 \%$ of BM erythroblasts, more than $15 \%$ of RS, a normal karyotype, and no $S F 3 B 1$ mutation but one SRSF2 and one TET2 mutation; three patients with a congenital sideroblastic anemia due to an ALAS2 mutation/deletion or a GLRX5 mutation; one patient with a severe $\beta$-thalassemia; and one patient with $S F 3 B 1^{\mathrm{K} 700 \mathrm{E}}$ MDS. By fluorescent PCR, ERFE ${ }^{\mathrm{WT}}$ was present, whereas $E R F E^{+12}$ was not detectable in any sample except the $S F 3 B 1^{\mathrm{K} 700 \mathrm{E}}$ MDS (Fig. 3F). This confirms that the onset of an aberrant $E R F E^{+12}$ is dependent not on the amplification of the erythroid compartment or the presence of RS but on the presence of a mutant SF3B1.

\section{Translation of $E R F E^{+12}$ into a variant protein that represses hepcidin}

Human ERFE encodes a 354-amino acid polypeptide. The addition of $12 \mathrm{nt}$ in ERFE mRNA generates an ERFE variant (further referred to as ERFE ${ }^{\mathrm{VPF}}$ ) containing a valine-proline-phenylalanineglutamine (VPFQ) insertion immediately upstream of the collagen domain (Fig. 4A and fig. S5A). To investigate whether the mutant $\mathrm{ERFE}^{\mathrm{VPFQ}}$ protein was produced in vivo, we prepared cell lysates of erythroblasts derived in culture from the $\mathrm{BM}$ $\mathrm{CD} 34^{+}$cells of patients with $S F 3 B 1^{\mathrm{MUT}}$ MDS. Through liquid chromatographytandem mass spectrometry (LC MS/MS) protein identification, we obtained several peptide-matching propositions including the ALHELGVYYLPDAEGAFR peptide (fig. S5B) already reported in public databases (www.proteomicsdb.org), and we identified a cryptic peptide VPFQFGLPGPPGPPGPQGPP GPIIPPEALLK corresponding to the VPFQ insertion at position 108 of ERFE (Fig. 4B). This confirms that the alternative $E R F E^{+12}$ transcript is translated into $\mathrm{ERFE}^{\mathrm{VPFQ}}$ in

Fig. 2. Differential splice junctions in SF3B $1^{\text {MUT }}$ MDSs. (A) Hierarchical clustering and heat map of differential splice junctions between $S F 3 B 1^{\mathrm{MUT}}$ and $S F 3 B 1^{\mathrm{WT}}$ MDS samples. Values indicating percent usage of the differential splice junction versus all other junctions sharing the same ss are normalized as $Z$ scores across patients and limited to a maximum of $|Z|=2$. Rows are splice junctions with indicated types: acceptor (red), donor (blue), ambiguous (green), and differentially expressed canonical junction (gray). Columns are patients. (B) Venn diagram of the number of differential alternative $5^{\prime}$ donor and $3^{\prime}$ acceptor junctions in $S F 3 B 1^{\mathrm{MUT}}$ compared to $S F 3 B 1^{\mathrm{WT}} \mathrm{MDS}$. The overlapping area represents ambiguous junctions ( $n=185$ ). (C) Distances between the alternative (AG') and canonical (AG) $3^{\prime}$ ss within the $50 \mathrm{nt}$ upstream of the AG plotted as a histogram. (D) Comparison of the expression of alternative junctions. The ratio $A G^{\prime} / A G^{\prime}+A G$ for each junction in $S F 3 B 1^{M U T}$ (red) versus $S F 3 B 1^{W T}$ (gray) MDS is shown. (E) Distribution of the biological functions of 63 genes affected by one or two aberrant 3'ss junctions located at $<50$ bases of the canonical 3 'ss, an additional sequence multiple of $3 \mathrm{nt}$, a ratio $A G^{\prime} /\left(A G^{\prime}+A G\right)>0.1$ in $S F 3 B 1^{M U T}$ samples, and an $F C>10$. (F) Ratio of $A G^{\prime} /\left(A G^{\prime}+A G\right)$ in 26 genes whose expression was up- or down-regulated in patients with $S F 3 B 1^{M U T}$. (G) Sashimi plot of 3 'ss canonical $\left({ }^{*}\right)$ and aberrant $\left.{ }^{* *}\right)$ junctions in the FAM132B/ERFE gene in three BM MNC samples, one SF $3 B 1^{\mathrm{WT}}$ and two $S F 3 B 1^{K 700 E} M D S$. The ratio $A G^{\prime} /\left(A^{\prime}+A G\right)$ is indicated in parentheses.
$S F 3 B 1^{\mathrm{MUT}}$ erythroblasts. 
Fig. 3. SF3B1-dependent expression of 3'ss aberrant $E R F E^{+12}$. (A) Induction of $E R F E^{+12}$ by expressing $S F 3 B 1^{\mathrm{K} 700 \mathrm{E}}$ in human $S F 3 B 1^{\mathrm{WT}}$ UT-7/ EPO cell line. Cells were transfected with a pLVX plasmid encoding a synthetic $S F 3 B 1^{W T}$ or $S F 3 B 1^{\text {K700E }}$ CDNA. Nontransfected (NT) UT-7/EPO cells are shown as a control. The canonical ERFE and aberrant $E R F E^{+12}$ transcripts were detected by capillary electrophoresis of fluorescent $P C R$ products. The $x$ axis represents molecular size (nt for nucleotides) of PCR amplicons, and the $y$ axis represents relative fluorescent units (RFU). The peak at $150 \mathrm{nt}$ corresponds to the canonical transcript, whereas the peak at $162 \mathrm{nt}$ refers to the alternative transcript due to cryptic AG' usage. (B) Analysis of alternative $A G^{\prime}$ and canonical $A G$ usage of ERFE and ENOSF1 minigenes transfected into murine CRISPR-Cas9 SF3B $1^{\mathrm{WT}}$ (clone 9.2) and SF $3 B 1^{\mathrm{K} 700 \mathrm{E}}$ (clone 5.13H) G1E-ER4 cells by fluorescent PCR. Transfected and NT parental G1E-ER4 cells are shown as controls. The peak at $135 \mathrm{nt}$ corresponds to the transcript generated by a canonical AG usage, whereas the peak at $147 \mathrm{nt}$ refers to the alternative transcript due to cryptic AG' usage. (C) Detection of $E R F E^{+12}$ depends on the presence of an SF3B1 mutant in MDS. BM MNC RNAs from three patients with $S F 3 B 1$ mutations $\left(S F 3 B 1^{\mathrm{K} 700 \mathrm{E}}\right.$, $S F 3 B 1^{\mathrm{H} 622 \mathrm{Q}}$, and $S F 3 B 1^{\mathrm{N} 626 \mathrm{D}}$ ), three with mutations in other splice genes $\left(U 2 A F 1^{\mathrm{Q} 157 \mathrm{P}}, \mathrm{SRSF}^{\mathrm{P} 95 \mathrm{H}}\right.$, and

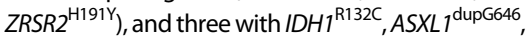
or no mutations were analyzed. ERFE $^{+12} /$ ERFE $^{+12}+$ $E R F E^{\mathrm{WT}}$ ratios are indicated. (D) Quantification of $E R F E^{\mathrm{WT}}$ and $E R F E^{+12}$ transcripts by RT-qPCR in BM samples depicted in (C). Results are expressed as normalized ratio quantities (NRQ) to ACTB and $B 2 M$ housekeeping genes. (E) Detection of $E R F E^{\mathrm{WT}}$ and $E R F E^{+12}$ transcripts in $S F 3 B 1^{\mathrm{MUT}}$ or $S F 3 B 1^{\mathrm{WT}}$ erythroid progenitors or basophilic/polychromatic erythroblasts (Baso/polyE) in culture in comparison with BM MNC. (F) Analysis of ERFE transcripts in $S F 3 B 1^{W T}$ diseases with ineffective erythropoiesis. The image shows peripheral blood (PB) MNC from one patient with MDS-RS with TET2 and SRSF2 and no SF3B1 mutations, samples from three patients with congenital sideroblastic anemias (two BM samples with ALAS2 mutation and one PB sample with GLRX5 mutation), and one PB sample from a patient with severe $\beta$-thalassemia ( $\beta$-Thal). Samples were analyzed by capillary electrophoresis of ERFE PCR products. One PB sample from a patient with $S F 3 B 1^{\mathrm{K} 700 \mathrm{E}} \mathrm{MDS}$ was used as a positive control.
A

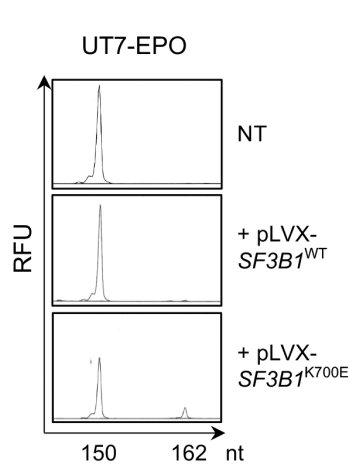

B

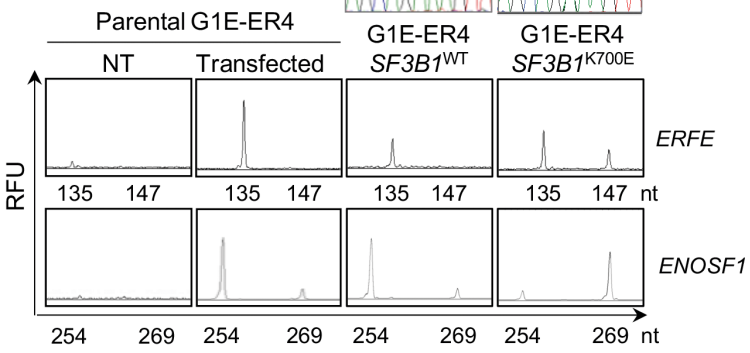

C

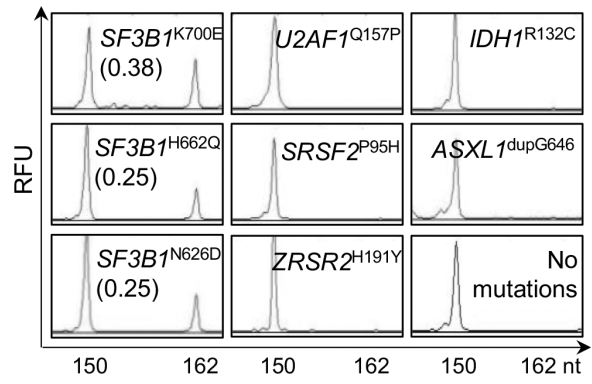

D
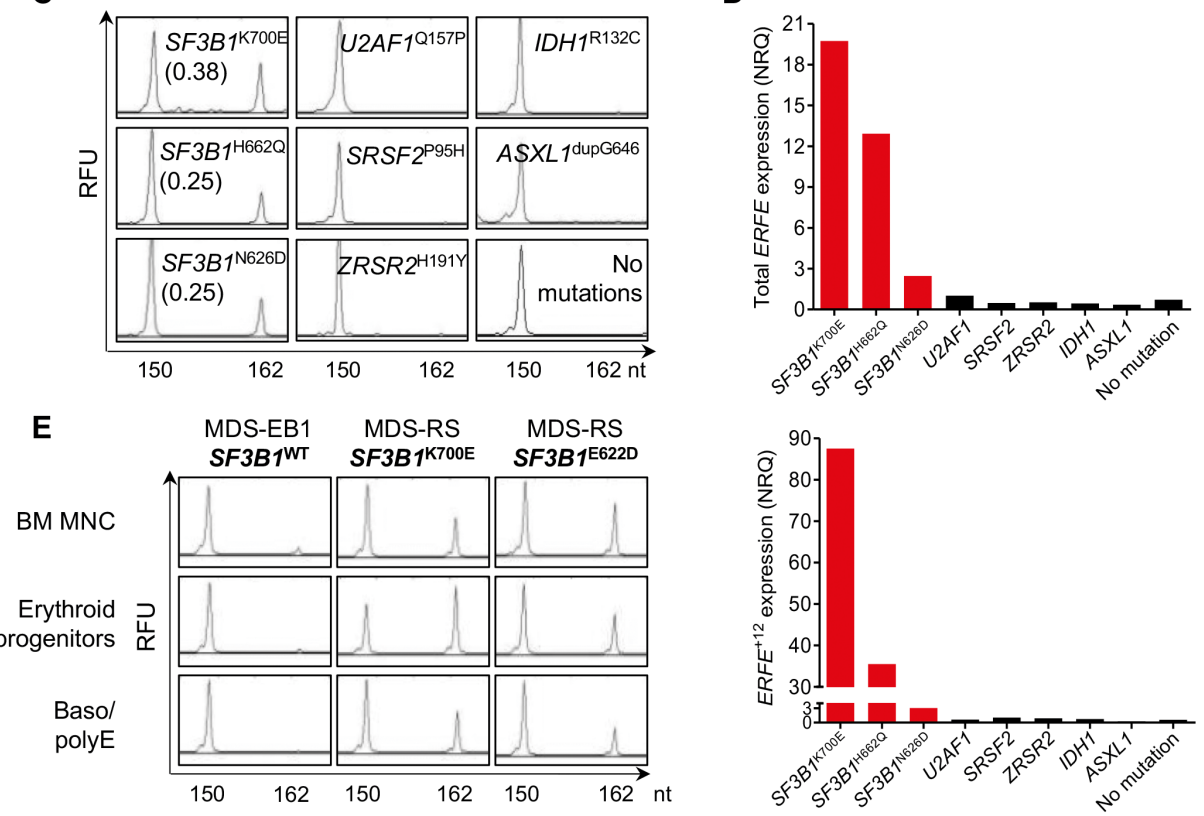

$\mathbf{F}$

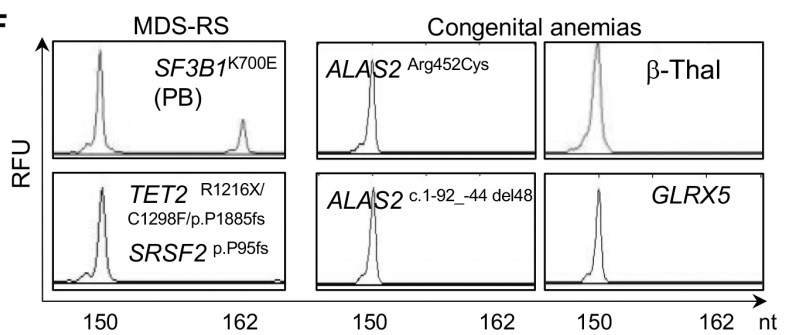

ERFE represses hepcidin in mice and contributes to pathological hepcidin suppression in patients with transfused and nontransfused $\beta$-thalassemia $(26,27)$. Whether $\mathrm{ERFE}^{\mathrm{VPFO}}$ also repressed hepcidin was tested. For this purpose, recombinant proteins ERFE ${ }^{W T}$ and $\mathrm{ERFE}^{\mathrm{VPFQ}}$ were produced in human embryonic kidney (HEK) $293 \mathrm{~F}$ cells. SDS-polyacrylamide gel electrophoresis analysis of $\mathrm{ERFE}^{\mathrm{WT}}$ and ERFE ${ }^{\mathrm{VPQ}}$ in reducing and nonreducing conditions demonstrated that the insertion of four amino acids does not change the molecular weight of the protein or its multimerization pattern, such that both proteins were predominantly found in high-molecular mass forms (>250 kDa) and in a trimeric form of $\sim 200 \mathrm{kDa}$ (Fig. 4C).
Then, Hep3B and HepG2 hepatocellular carcinoma cells were treated for 16 hours with purified $\mathrm{ERFE}^{\mathrm{VPFQ}}$ or ERFE ${ }^{\mathrm{WT}}$. Both proteins similarly caused a fivefold reduction in the expression of HAMP mRNA encoding hepcidin compared to controls (Fig. 4D). These data indicate that insertion of four amino acids upstream of the collagen domain did not affect the bioactivity of the protein.

\section{Prediction of hyperferritinemia by overproduction of ERFE in $S F 3 B 1^{\text {MUT }}$ MDS}

We then measured the plasma concentration of ERFE in the training cohort of 156 patients with MDS and 20 healthy non-blood donor 


$\begin{array}{lcr}\mathbf{N} & \text { ERFEWT } & \mathbf{C} \\ \text { MLFVRQSDKGVNGKKRSRGKAKKLK FGLPGPPGPPGPQGPPGPIIPPEALLKEFQLLLKG } \\ \mathbf{N} \quad \text { ERFEVPFQ } \\ \text { MLFVRQSDKGVNGKKRSRGKAKKLKVPFQ FGLPGPPGPPGPQGPPGPIIPPEALLKEFOLLLKG }\end{array}$

B

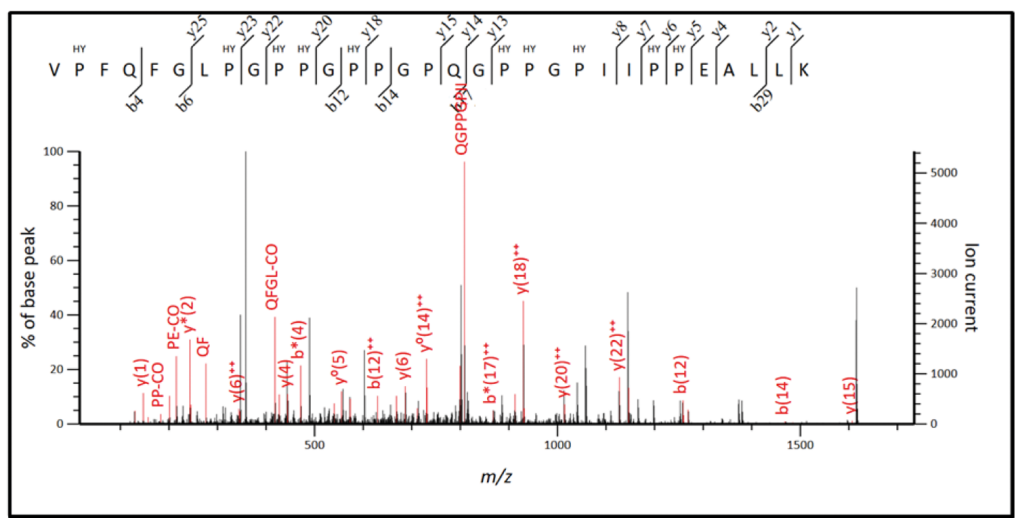

C

D
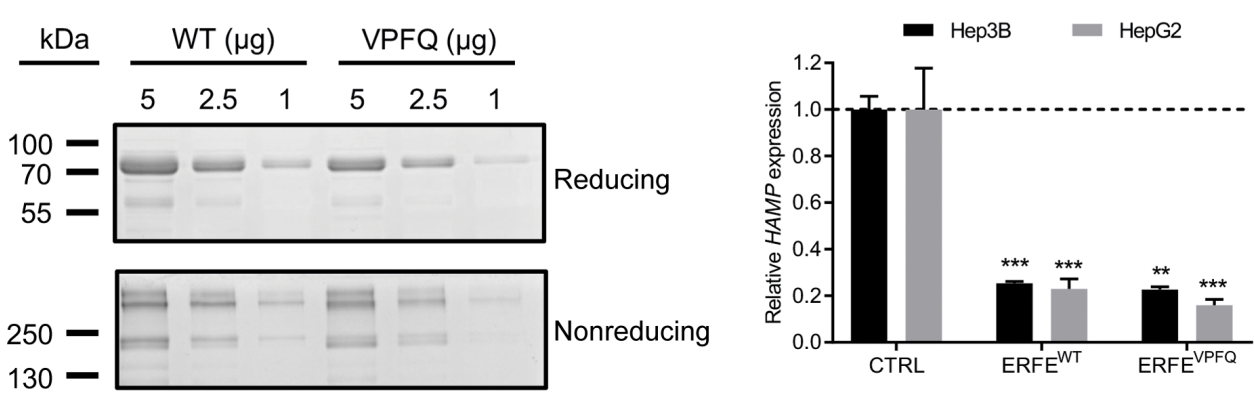

Fig. 4. Identification of ERFE ${ }^{\mathrm{VPF}}$ peptide by mass spectrometry and hepcidin repression by recombinant ERFE ${ }^{\mathrm{VPFQ}}$ protein. (A) Amino acid sequence of ERFE ${ }^{\mathrm{WT}}$ and ERFE ${ }^{\mathrm{VPFQ}}$ peptides. VPFQ (red), collagen domain (blue). (B) Identification of a specific ERFE ${ }^{\mathrm{VPF}}$ peptide in erythroblast cell lysates by mass spectrometry using nano liquid chromatography coupled with a Q Exactive Plus mass spectrometer. The calculated peptide mass was 3227.650782 from $3+$ ion observed at mass/charge ratio $(\mathrm{m} / \mathrm{z}) 1076.890870$ with measured $\Delta=3.6 \mathrm{ppm}$, Mascot score $=17$, expectation value $=0.069 \mathrm{HY}$, hydroxylated proline residues. $($ C) SDS-polyacrylamide gel electrophoresis and Coomassie blue staining of purified ERFE ${ }^{\mathrm{WT}}$ and ERFE ${ }^{\mathrm{VPFQ}}$ in reducing and nonreducing conditions. (D) Hep3B and HepG2 hepatocellular carcinoma cells were treated with purified recombinant human $\operatorname{ERFE}^{\mathrm{WT}}$ or $\mathrm{ERFE}^{\mathrm{VPFQ}}(2 \mu \mathrm{g} / \mathrm{ml})$ for 16 hours. HAMP was quantified by RT-qPCR and normalized to HPRT. Data shown are means \pm SEM of three independent experiments and represent an FC of hepcidin mRNA expression in ERFE-treated compared to untreated (CTRL) cells. Two-tailed Student $t$ test for $P$ values; ${ }^{* * *} P<0.0001 ;{ }^{* *} P<0.001$.

controls using a validated immunoassay (27). We first verified that the ERFE immunoassay was able to detect both ERFE ${ }^{\mathrm{WT}}$ and ERFE ${ }^{\mathrm{VPFQ}}$ Human ERFE enzyme-linked immunosorbent assay (ELISA) detected similar amounts $(1 \mu \mathrm{g} / \mathrm{ml})$ of each recombinant protein in the supernatants of HEK $293 \mathrm{~F}$ cells transiently transfected with ERFE ${ }^{\mathrm{WT}}$ and ERFE ${ }^{\mathrm{VPF}}$ expression vectors. This established that both isoforms were detectable by ELISA. The mean concentration of ERFE in $S F 3 B 1^{\mathrm{MUT}}$ or $S F 3 B 1^{\mathrm{WT}}$ MDS was higher than that in 20 non-blood donor healthy controls $(P<0.0001$; Fig. 5A). Among the MDS samples, the ERFE concentration was higher in $S F 3 B 1^{\mathrm{MUT}}(135.0 \pm 72.5 \mathrm{ng} / \mathrm{ml})$ compared to $S F 3 B 1^{\mathrm{WT}}(62.1 \pm 36.7 \mathrm{ng} / \mathrm{ml})$ MDS $(P<0.0001$; Fig. 5A). High concentrations of circulating ERFE correlated with high expression of $E R F E^{+12}$ transcript (Pearson test; $P<0.0001$; fig. S6A). Consistently, the ERFE concentration was also higher in MDS-RS compared to all other World Health Organization (WHO) MDS subtypes (fig. S6B). Ferritin concentrations were significantly higher in patients with $S F 3 B 1^{\mathrm{MUT}}$ compared to patients with SF3B1 ${ }^{\mathrm{WT}}(P<0.0001$; Fig. 5B). We also measured plasma hepcidin and confirmed that the concentration of hepcidin in $S F 3 B 1^{\mathrm{MUT}}$ MDS was significantly lower compared to $S F 3 B 1^{\mathrm{WT}} \mathrm{MDS}$ $(P=0.031$; Fig. $5 C)$. We found no difference between SF3B1 ${ }^{\mathrm{MUT}}$ MDS and healthy controls. The hepcidin/ferritin ratio was lower in $S F 3 B 1^{\mathrm{MUT}}$ than in $S F 3 B 1^{\text {WT }}$ MDS $(P<0.0001$; Fig. 5D) and also in MDS-RS compared to other WHO subtypes (fig. S6C), as a result of both a lower concentration of hepcidin and a higher concentration of ferritin in patients with $S F 3 B 1^{\mathrm{MUT}}$. The plasma concentration of ERFE was inversely correlated to the hepcidin/ferritin ratio (Pearson test; $P<0.0001 ; r=0.600$; fig. S6D). Our analysis also highlights that an ERFE concentration above a threshold of $100 \mathrm{ng} / \mathrm{ml}$ repressed hepcidin more efficiently (fig. S6D). Serum EPO concentration was equally increased in patients with $S F 3 B 1^{\mathrm{MUT}}$ and $S F 3 B 1^{\mathrm{WT}}$ compared to normal values ( 5 to $36 \mathrm{U} /$ liter; table $\mathrm{S} 1$ ), and although ERFE is regulated by erythropoietin in mice, we did not find any correlation between serum EPO and ERFE concentration (fig. S6E) (26). The increased concentration of plasma ERFE was associated with a more pronounced degree of ineffective erythropoiesis, as assessed by a significant increase in plasma concentration of soluble transferrin receptor (sTfR) in $S F 3 B 1^{\mathrm{MUT}}$ compared to patients with $S F 3 B 1^{\mathrm{WT}}$ MDS $(P<0.0001$; fig. S6F).

To validate these findings, we prospectively enrolled an external cohort of patients with lower-risk MDS in our study until the proportion of patients with $S F 3 B 1^{\text {MUT }}$ MDS was comparable to that in the training cohort (table S5). This validation cohort consisted of 55 patients with MDS, 42 (76.3\%) of whom had MDS with SF3B1 mutation. Patients with $S F 3 B 1^{\mathrm{MUT}}$ and $S F 3 B 1^{\mathrm{WT}}$ in this cohort had a similar transfusion burden with a mean number of 4 red blood cell (RBC) units per 8 weeks (table S5). The mean concentrations of ERFE and ferritin significantly increased $(P=0.0005$ and $P=0.0488$, respectively; Fig. 5, E and F), whereas hepcidin and hepcidin/ferritin ratio significantly decreased in patients with $S F 3 B 1^{\mathrm{MUT}}(P=0.0038$ and 


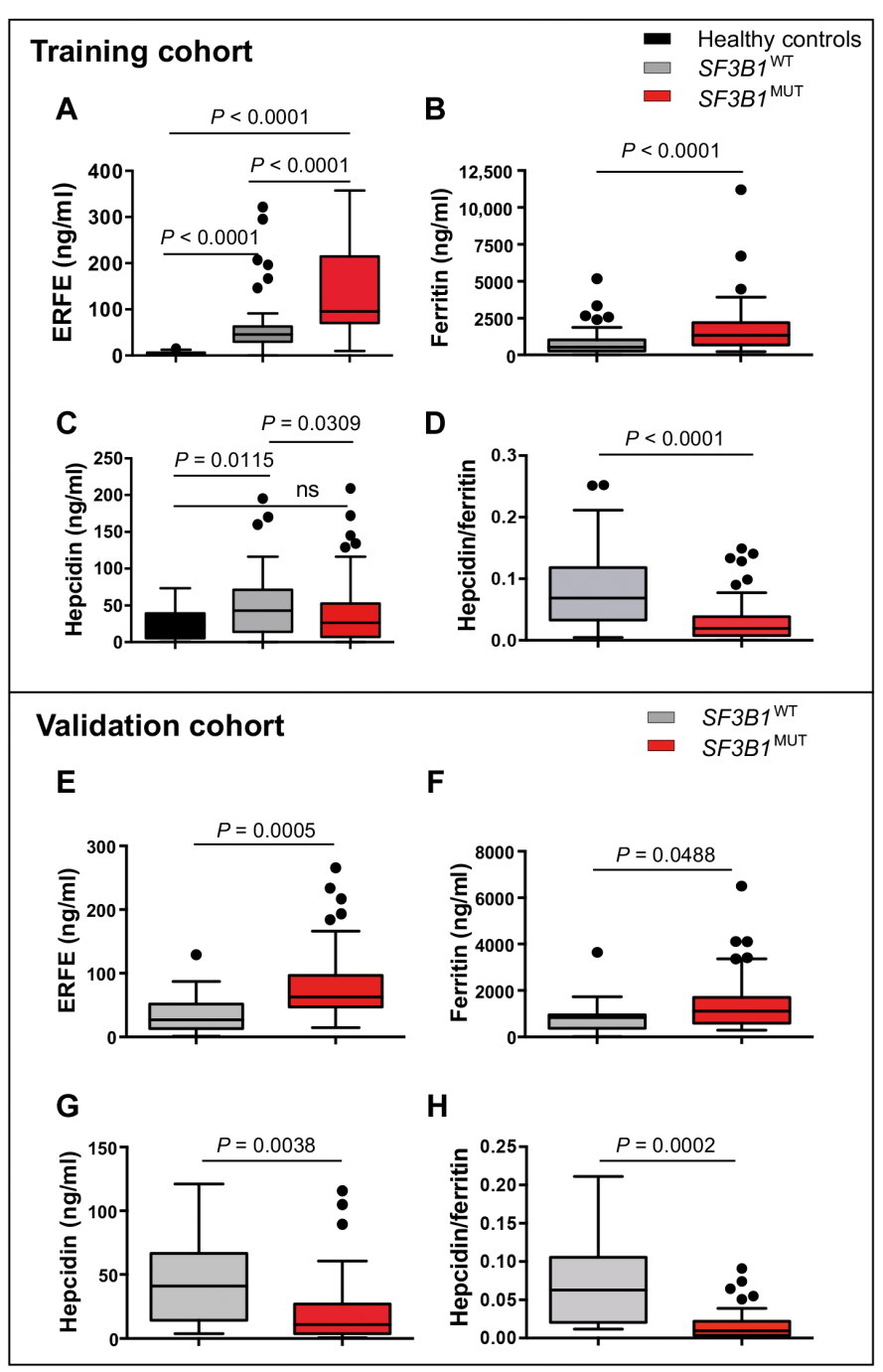

Fig. 5. Increased plasma concentration of ERFE in patients with SF3B1 ${ }^{\text {MUT }}$ MDS. Quantitative analysis was performed in plasma samples collected from 20 nonblood donor healthy volunteers (black), 156 patients with MDS including 94 SF3B $1^{\text {MUT }}$ (red) and 62 SF3B $1^{\mathrm{WT}}$ (gray) representing the training cohort (A to D), and 55 patients with MDS including 42 SF3B1 $1^{\mathrm{MUT}}$ (red) and 13 SF3B1 ${ }^{\mathrm{WT}}$ (gray) representing the validation cohort (E to $\mathbf{H})$. The graphs show quantification of erythroferrone ( $A$ and $E$ ), ferritin ( $B$ and $F$ ), hepcidin ( $C$ and $G$ ), and hepcidin/ferritin ratio ( $D$ and $H$ ). Results are expressed as medians and interquartile ranges (IQRs). The boxplots represent the median and the first and third quartiles, and the whiskers represent the lowest and the highest values still within the 1.5 IQR of the lower and upper quartiles. Mann-Whitney for $P$ values.

$P=0.0002$, respectively; Fig. 5, G and $\mathrm{H}$ ). This confirms the results of the training cohort and suggests that the increase of ERFE concentration in patients with $S F 3 B 1^{\mathrm{MUT}} \mathrm{MDS}$ is independent of RBC transfusions.

Iron homeostasis changes after RBC transfusions, which ameliorate the anemia and increase the concentrations of circulating iron, with both effects expected to increase hepcidin. To assess the influence of RBC transfusion in our analysis, we delineated a subset of 61 patients with MDS in the training cohort, including 25 patients with $S F 3 B 1^{\mathrm{MUT}}$ and $36 S F 3 B 1^{\mathrm{WT}}$ with a low transfusion burden before inclusion ( $<4 \mathrm{RBC}$ units per 8 weeks). In this subset, patients with
$S F 3 B 1^{\mathrm{MUT}}$ or $S F 3 B 1^{\mathrm{WT}}$ MDS were equally transfused (mean, $0.5 \mathrm{RBC}$ unit/8 weeks), but ferritin and plasma iron concentrations remained higher in patients with SF3B1 $1^{\text {MUT }}$ (fig. S7, A and B). The hepcidin/ ferritin and hepcidin/plasma iron ratios were significantly lower in patients with $S F 3 B 1^{\mathrm{MUT}}$ ( $P<0.0001$ and $P=0.019$, respectively; fig. S7, $C$ and D), and the circulating ERFE concentration remained significantly increased in low transfusion burden patients with $S F 3 B 1^{\text {MUT }}$ compared to patients with $S F 3 B 1^{\text {WT }}(P<0.0001$; fig. S7E). Erythropoiesis-stimulating agents (ESAs) are used as first-line treatment of anemia, with low serum EPO and low transfusion burden as predictors of response (23). We investigated the impact of iron parameters on the response to epoetin $\zeta$ for 12 weeks in 59 patients with low-risk MDS included in a clinical trial of the Groupe Francophone des Myélodysplasies (GFM), GFM-Retacrit-2013 (NCT 03598582; table S6) (30). Plasma ERFE, ferritin, and hepcidin concentrations at enrollment were similar in responding and nonresponding patients, suggesting that these parameters were not predictive of the erythropoietic response in this cohort (fig. S8). We then explored the determinants of hyperferritinemia $>300 \mu \mathrm{g} / \mathrm{ml}$ in patients with low transfusion burden. By univariate analysis, ERFE $(P=0.005)$, hepcidin $(P=0.013)$, and SF3B1 mutation $(P=0.006)$, but not sTfR concentration or the number of transfused RBC units, were significantly linked to the concentration of serum ferritin (Table 1). By multivariate analysis, ERFE, hepcidin, and SF3B1 mutation remained independent predictors of high ferritin concentration (Table 1). Together, these results indicate that before patients reach a critical threshold of transfusion dependence, hyperferritinemia can be caused by $S F 3 B 1^{\mathrm{MUT}}$-induced expression of ERFE, which in turn lowers hepcidin.

\section{Erythroid lineage-restricted expression of $E R F E^{+12}$}

In mice, ERFE mRNA expression in the BM is regulated by EPO and is predominant in basophilic and polychromatic erythroblasts (26). To investigate whether ERFE and $E R F E^{+12}$ expression is restricted to the erythroid lineage, we amplified in parallel the erythroid and granulocytic precursors derived from the BM CD34 $4^{+}$cells of one $S F 3 B 1^{\text {MUT }}$ and one $S F 3 B 1^{\mathrm{WT}}$ sample. The purity of each lineage was assessed by the cytological examination of May-Grünwald-Giemsa-stained cytospins, and the quantification of lineage-restricted markers was assessed by RT-qPCR (Fig. 6A and fig. S9A). To compare the amount of each transcript isoform at the different stages of differentiation, we quantified the canonical $E R F E^{\mathrm{WT}}$ and the aberrant $E R F E^{+12}$ by RT-qPCR. The expression of the canonical transcript $E R F E^{\mathrm{WT}}$ expressed as normalized ratio quantities (NRQ) increased in both $S F 3 B 1^{\text {MUT }}$ and $S F 3 B 1^{\text {WT }}$ MDS erythroblasts. In granulocytes, the expression of $E R F E^{\mathrm{WT}}$ was close to the limit of detection (Fig. 6B). The expression of $E R F E^{+12}$ was restricted to the erythroid lineage, increased with the differentiation of $S F 3 B 1^{\text {MUT }}$ erythroblasts, and was higher in $S F 3 B 1^{\text {MUT }}$ compared to $S F 3 B 1^{\text {WT }}$ erythroblasts (Fig. 6B). These results indicate that $E R F E^{+12}$ expression is specific to the erythroid lineage.

The SF3B1 gene is mutated in 15\% of patients suffering from CLL, and the SF3B1 ${ }^{\text {MUT }}$ allele is present in $\mathrm{CD}_{19^{+}}$lymphocytes $(14,31)$. To investigate whether ERFE ${ }^{+12}$ was detectable in SF3B1 $1^{\text {MUT }}$ CLL, we collected one sample from a patient with CLL followed by MDS, whose BM MNC expressed a clonal SF3B1 ${ }^{\mathrm{K} 700 \mathrm{E}}$ mutation, and three peripheral blood (PB) MNC samples from two patients with CLL, one of whom harbored a clonal $S F 3 B 1^{\text {T663I }}$ mutation with a variant allele frequency of more than $40 \%$ and the second had no mutation 
Table 1. Erythroferrone, hepcidin, and SF3B1 mutation as independent predictors of hyperferritinemia in low transfusion burden patients with MDS. Erythroferrone, hepcidin, sTfR, number of RBC units per 8 weeks, and SF3B1 mutation were evaluated in the group of 60 patients receiving less than 4 RBC units per 8 weeks on the basis of ferritin with a cutoff value of $300 \mathrm{ng} / \mathrm{ml}$. Parameters are indicated as means and $95 \%$ confidence intervals $(95 \% \mathrm{Cl})$ or ranges. For univariate analysis, Mann-Whitney and $\chi^{2}$ tests were used to compare the variables between $S F 3 B 1^{\mathrm{MUT}}$ and $S F 3 B 1^{\mathrm{WT}}$ MDS. Multivariate logistic regression analysis was performed for variables with $P$ value $<0.1$ in univariate analysis.

\begin{tabular}{|c|c|c|c|c|}
\hline Parameters & Ferritin $<300 \mathrm{ng} / \mathrm{ml}$ & Ferritin $\geq 300 \mathrm{ng} / \mathrm{ml}$ & Univariate & Multivariate \\
\hline & $n=19$ & $n=41$ & $P$ value & $P$ value \\
\hline $\begin{array}{l}\text { Erythroferrone }(\mathrm{ng} / \mathrm{ml}) \text {, } \\
\text { mean }(95 \% \mathrm{Cl})\end{array}$ & $36.7(26.8-46.6)$ & $72.7(55.4-90.0)$ & 0.005 & 0.002 \\
\hline sTfR (ng/ml), mean $(95 \% \mathrm{Cl})$ & $1.21(0.99-1.43)$ & $1.42(1.18-1.65)$ & 0.484 & \\
\hline SF3B1 mutation yes, $n$ (\%) & $3(15.8)$ & $22(53.6)$ & 0.006 & 0.023 \\
\hline
\end{tabular}

in the $S F 3 B 1$ gene, and from a patient with $S F 3 B 1^{\mathrm{K} 700 \mathrm{E}} \mathrm{MDS}$. We analyzed the MAP $3 K 7$ transcript, which is alternatively spliced in $S F 3 B 1^{\text {MUT }}$ CLL or MDS using a cryptic 3'ss $(14,32)$. A 170 -nt fragment corresponding to the alternative $M A P 3 K 7$ transcript was enriched in all $S F 3 B 1^{\mathrm{MUT}}$ samples compared to the $S F 3 B 1^{\mathrm{WT}}$ CLL (Fig. 6C). ERFE ${ }^{+12}$ was detected in the PB MNC of the $S F 3 B 1^{\mathrm{K} 700 \mathrm{E}}$ MDS but not in the $S F 3 B 1^{\text {T663I }}$ or $S F 3 B 1^{\text {WT }}$ CLL. ERFE ${ }^{+12}$ was not detected in the BM MNC of the $S F 3 B 1^{\mathrm{K} 700 \mathrm{E}} \mathrm{CLL}+\mathrm{MDS}$ sample. To get further insights into the cell types expressing $E R F E^{+12}$, we sorted $\mathrm{CD} 9^{+} \mathrm{CD}^{-} \mathrm{B}$ cells, $\mathrm{CD} 19^{+} \mathrm{CD}^{+}$pathological B cells, and $\mathrm{CD}^{+}$ $\mathrm{T}$ cells and myeloid cells containing erythroblasts from the BM MNC fraction of the patients with $S F 3 B 1^{\mathrm{K} 700 \mathrm{E}} \mathrm{CLL}+\mathrm{MDS}, S F 3 B 1^{\mathrm{K} 700 \mathrm{E}}$ MDS, and $S F 3 B 1^{\text {WT }}$ MDS and from the PB MNC of the patient with $S F 3 B 1^{T 663 I}$ CLL (fig. S9B). The number of cells in the myeloid fraction of $S F 3 B 1^{\text {T663I }}$ CLL was too small for further studies. The 170-nt fragment of $M A P 3 K 7$ was detected in $\mathrm{CD}^{1} 9^{+} \mathrm{CD}^{+}$pathological B cells of $S F 3 B 1^{\mathrm{K} 700 \mathrm{E}} \mathrm{CLL}+\mathrm{MDS}$ and $S F 3 B 1^{\mathrm{T} 663 \mathrm{I}}$ CLL and also in the myeloid fraction but not in the $\mathrm{CD} 19^{+} \mathrm{CD}^{-} \mathrm{B}$ cells of $S F 3 B 1^{\mathrm{K} 700 \mathrm{E}}$ MDS (Fig. 6D). By sequencing SF3B1 RNA, we demonstrated that the mutation was present in the cell populations in which the alternative $M A P 3 K 7$ transcript was detected (Fig. 6E). The alternative $E R F E^{+12}$ transcript was not detected in the $\mathrm{CD} 19^{+} \mathrm{CD}^{+}$pathological B cells of SF3B $1^{\mathrm{K} 700 \mathrm{E}} \mathrm{MDS}+\mathrm{CLL}$ or SF3B $1^{\mathrm{T} 663 \mathrm{I}} \mathrm{CLL}$, and its expression was restricted to $S F 3 B 1^{\mathrm{K} 700 \mathrm{E}}$ myeloid MDS cells. Together, these results indicate that $E R F E$ is expressed in erythroid cells and $E R F E^{+12}$ is restricted to $S F 3 B 1^{\text {MUT }}$ MDS myeloid cells.

\section{Correlation between changes in ERFE ${ }^{+12}$ expression and the response to lenalidomide}

Fifty percent of patients with lower-risk MDS, including patients with MDS-RS, experience primary resistance or secondary failure to treatments they receive to cure their anemia. Whether the mechanism of resistance involves the persistence of clonal erythropoiesis is always unknown. We have previously shown that lenalidomide administered to patients with ESA-resistant non-del(5q) MDS targets the malignant clone and, in some cases, eliminates the dominant $S F 3 B 1^{\text {MUT }}$ clone for the duration of response (33). However, the frequency of the SF3B1 variant allele, which is expressed in erythroid and myeloid cells, does not only reflect the abundance of clonal erythroblasts. Here, we retrospectively monitored the expression of erythroid-specific $E R F E^{+12}$ transcript for the follow-up of patients included in clinical trials of the GFM: GFM-Retacrit-2013 and GFM-LenEpo-2008 (30,34). For this purpose, we performed a fluorescent PCR and integrated $E R F E^{+12}$ and $E R F E^{\mathrm{WT}}$ peak heights as a ratio $E R F E^{+12} / E R F E^{+12}+E R F E^{\mathrm{WT}}$ in patients with $S F 3 B 1^{\mathrm{MUT}}$ MDS. Then, the ratio was measured in paired RNA samples at enrollment and first evaluation. In GFM-Retacrit-2013, four nonresponders and six responders were compared, and no significant variation was observed (Fig. 7A and fig. S10A). By contrast, in GFM-LenEpo-2008, the ratio $E R F E^{+12} / E R F E^{+12}+E R F E^{\mathrm{WT}}$ decreased in six responding patients but remained stable in eight nonresponding patients (Fig. 7B and fig. S10B). The percent variation of ratios between samples obtained during screening and after four cycles of treatment was significantly different between responding and nonresponding patients (Mann-Whitney test, $P=0.0013$; Fig. 7B, right). The percent variation of $S F 3 B 1$ variant allele frequency in BM MNCs between screening and evaluation after four cycles was not significantly different between nonresponding and responding patients (fig. S10C). This confirms that lenalidomide may target clonal erythropoiesis. By contrast, ERFE protein quantities did not vary with the response in both cohorts (fig. S11). Last, we addressed the prognostic value of the $E R F E^{+12} / E R F E^{+12}+E R F E^{\mathrm{WT}}$ ratio for overall survival (OS) in a cohort of 90 patients with low-risk MDS, including 24 patients with $S F 3 B 1^{\mathrm{MUT}}$ and 66 with $S F 3 B 1^{\text {WT }}$ enrolled at diagnosis with a median follow-up of 36.9 months (table S7). In this cohort, a receiver operating characteristic (ROC) analysis established that a value of 0.008 was the threshold of positivity of the $E R F E^{+12} / E R F E^{+12}+E R F E^{\mathrm{WT}}$ ratio with a specificity and sensitivity of $100 \%$. As shown in Fig. 7C, an $E R F E^{+12} / E R F E^{+12}+E R F E^{\mathrm{WT}}$ ratio $>0.008$ was predictive of better OS (log-rank test; $P=0.019)$ and was correlated with the presence of an SF3B1 mutation. Among patients expressing the variant $E R F E^{+12}$ transcript, there was no significant correlation between $E R F E^{+12}$ / $E R F E^{+12}+E R F E^{\mathrm{WT}}$ ratio and OS (log-rank test; $P=0.064$; fig. S12). Our results suggest that $E R F E^{+12}$ expression may correlate with OS for patients with $S F 3 B 1^{\mathrm{MUT}}$ MDS.

\section{DISCUSSION}

In this study, we show that in patients with $S F 3 B 1^{\mathrm{MUT}}$ MDS, an alternative FAM132B/ERFE ${ }^{+12}$ transcript is translated into an ERFE ${ }^{\mathrm{VPF}}$ 
A

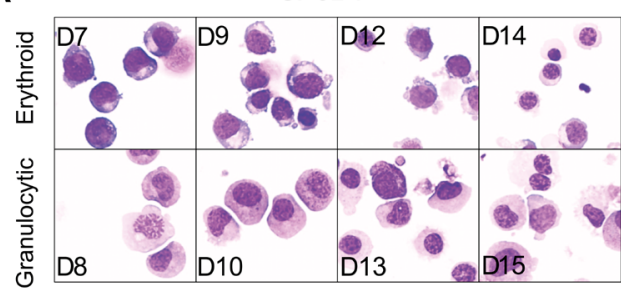

B

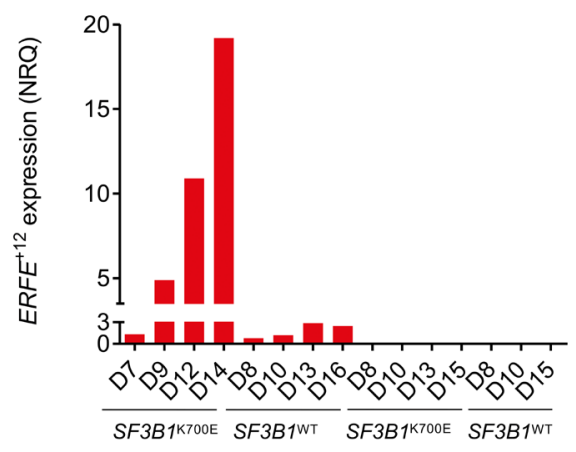

C

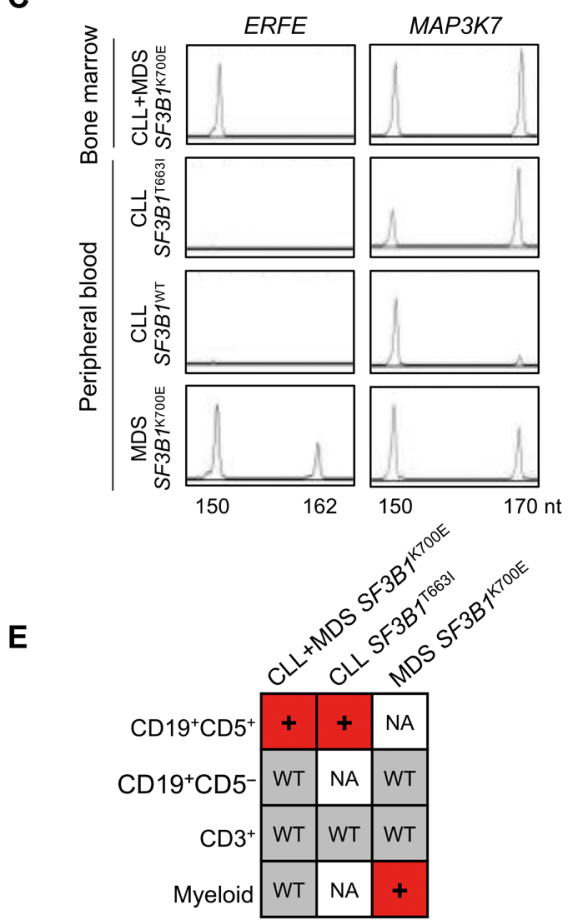

Fig. 6. Erythroid cell-restricted expression of $\operatorname{ERFE}^{+12}$. (A) May-Grünwald-Giemsa-stained cytospins of erythroid and granulocytic precursors obtained from liquid culture of $B M S F 3 B 1^{\mathrm{WT}}$ or $S F 3 B 1^{\mathrm{K} 700 \mathrm{E}} \mathrm{CD} 34^{+}$progenitors. (B) Quantification of $E R F E^{\mathrm{WT}}$ and $E R F E^{+12}$ in erythroid and granulocytic precursors by RT-qPCR. Results are expressed as NRQ $\pm \mathrm{SEM}$ to $A C T B$ and $B 2 M$ housekeeping genes. (C) $E R F E^{+12}$ is absent in $S F 3 B 1^{\mathrm{MUT}} \mathrm{CLL}$. BM MNCs from a patient with $S F 3 B 1^{\mathrm{K} 700 \mathrm{E}} \mathrm{CLL}+\mathrm{MDS}$ or PB MNCs from patients with $S F 3 B 1^{T 6631} \mathrm{CLL}, S F 3 B 1^{\mathrm{WT}} \mathrm{CLL}$, and $S F 3 B 1^{\mathrm{K} 700 \mathrm{E}} \mathrm{MDS}$ were collected for analysis by capillary electrophoresis of ERFE and MAP3K7 fluorescent PCR products. ERFE ${ }^{+12}$ was detected as a 162 -nt fragment and $M A P 3 K 7^{+20}$ was detected as a 170 -nt fragment. PB samples from one patient with an $S F 3 B 1^{\mathrm{WT}} \mathrm{CLL}$ and one patient with an $S F 3 B 1^{\mathrm{MUT}} \mathrm{MDS}$ are shown as controls. (D) $E R F E^{+12}$ expression is restricted to $S F 3 B 1^{\mathrm{MUT}}$ myeloid lineage. $\mathrm{CD} 19^{+} \mathrm{CD} 5^{-} \mathrm{B}$ cells, $\mathrm{CD} 19^{+} \mathrm{CD} 5^{+} \mathrm{B} \mathrm{CLL}$ cells, $\mathrm{CD} 3^{+} \mathrm{T}$ cells, and myeloid cells were sorted from the BM MNC fraction of an $S F 3 B 1^{\mathrm{K} 700 \mathrm{E}} \mathrm{CLL}+\mathrm{MDS}$, an $S F 3 B 1^{\mathrm{K} 700 \mathrm{E}} \mathrm{MDS}$, and an $S F 3 B 1^{\mathrm{WT}} \mathrm{MDS}$ and from the PB MNCs of an SF3B1 ${ }^{\mathrm{T} 6631} \mathrm{CLL}$. ERFE and MAP3K7 transcripts were analyzed by fluorescent PCR. (E) The sequencing of SF3B1 was performed on CDNA of each cell fraction. + , mutated; WT, wild type; NA, not available. protein and, together with the canonical transcript, contributes to the overexpression of ERFE. Similarly to ERFE, the $\mathrm{ERFE}^{\mathrm{VPF}}$ protein efficiently represses hepcidin. ERFE ${ }^{+12}$ is specifically induced by the clonal erythropoiesis.

In $S F 3 B 1^{\mathrm{MUT}}$ cancers, alternative $3^{\prime} \mathrm{ss}$ usages are the most frequent splicing aberrancies $(11,13,14,35)$. The recently resolved crystal structure of the SF3b complex helps to understand this feature (36). In the spliceosome, the SF3b complex interacts with the pre-mRNA and is involved in the branch site selection during splicing. Mutations in SF3B1 affect the structure of the SF3b RNAbinding platform, resulting in the selection of alternative branch site and alternative transcripts, of which more than $50 \%$ are subjected to $\operatorname{NMD}(11,13,36)$. On the basis of these findings, we focused our attention on the transcripts generated by the use of an alternative $\mathrm{AG}^{\prime}$. The analysis of the distance separating $A G$ from $\mathrm{AG}^{\prime}$ revealed strong peaks at 15,18 , and $21 \mathrm{nt}$, showing that inserts could be multiples of $3 \mathrm{nt}$. Among alternative inframe junctions, we identified two regulators of iron homeostasis, $A B C B 7$ and ERFE. As already reported, the alternative $A B C B 7$ mRNA results from the addition of 21 nt between exons 8 and 9 and, in our sample set, was slightly down-regulated in SF3B $1^{\text {MUT }}$ compared to $S F 3 B 1^{\mathrm{WT}}$ MDS $(11,32,37)$. By contrast, the aberrant $E R F E$ transcript modified by the addition of $12 \mathrm{nt}$ was up-regulated 2.3-fold in $S F 3 B 1^{\text {MUT }}$ MDS. ERFE ${ }^{+12}$ has not been reported in other $S F 3 B 1^{\mathrm{MUT}}$ cancers despite some overlap between the sets of alternative 3 'ss transcripts in $S F 3 B 1^{\mathrm{MUT}}$ uveal melanoma, CLL, and MDS $(11,13,14,38,39)$. We showed the existence of a variant protein containing VPFQ sequence immediately upstream of the collagen domain, which is putatively involved in protein-protein interactions in other CTRP family members (40). VPFQ may not influence protein conformation, because the apparent molecular weight was similar for recombinant ERFE ${ }^{\mathrm{WT}}$ and $\mathrm{ERFE}^{\mathrm{VPFQ}}$ proteins, which both repressed HAMP gene expression. However, we could not exclude an effect of the VPFQ insertion on protein stability and/or still unknown functions.

In MDS, serum EPO is increased but ineffective in stimulating erythropoiesis because maturing erythroid cells undergo 

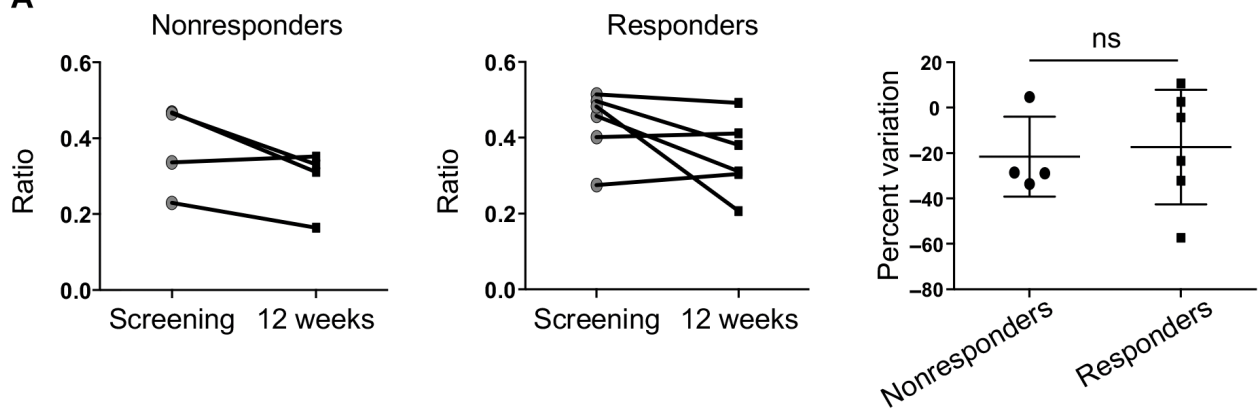

B
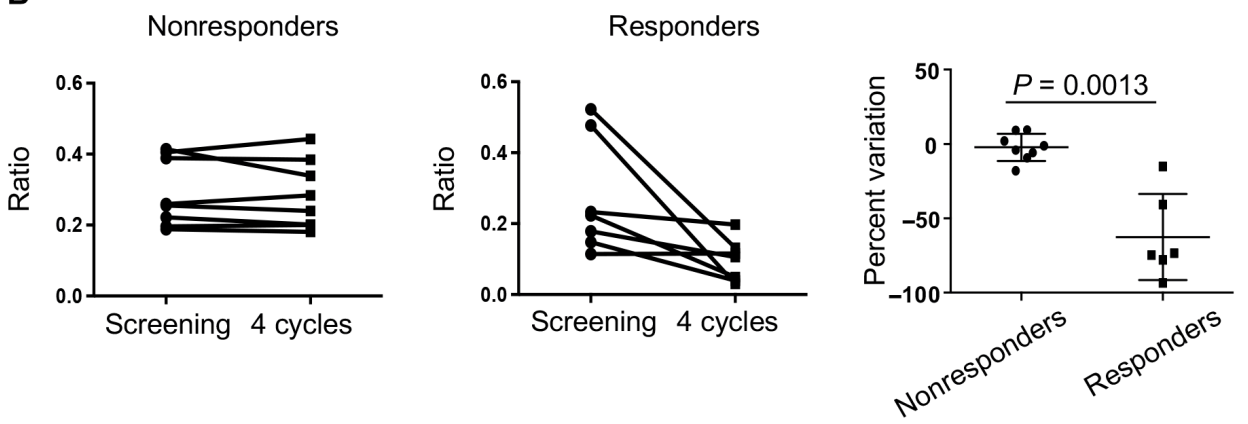

C

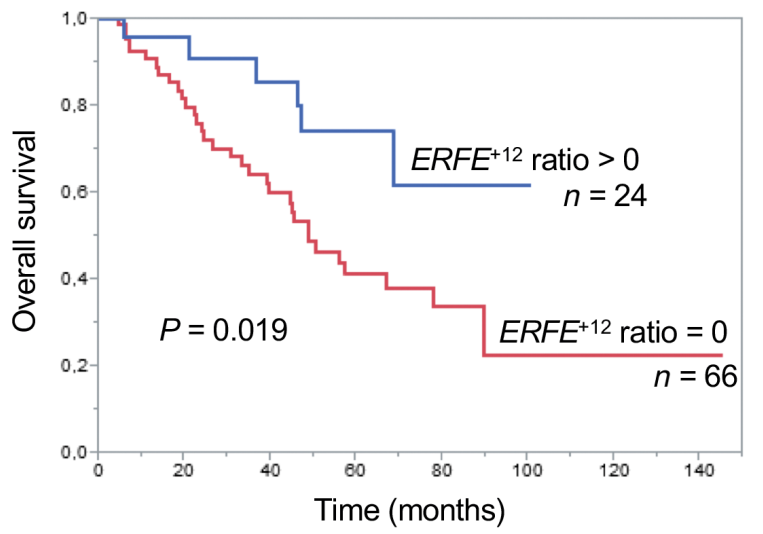

Fig. 7. ERFE ${ }^{+12}$ expression as a marker of clonal erythropoiesis and survival. Fluorescent $P C R$ was performed at screening and evaluation in (A) 10 paired samples from patients with SF $3 B 1^{\text {MUT }}$ MDS enrolled in the GFM-Retacrit-2013 clinical trial (four nonresponding and six responding patients) and (B) 14 paired samples from patients with SF3B $1^{\text {MUT }}$ MDS enrolled in the GFM-LenEpo-2008 clinical trial (eight nonresponding and six responding patients). Peak heights of $E R F E^{+12}$ and $E R F E^{\mathrm{WT}}$ signals were integrated as $E R F E^{+12} / E F E^{+12}+E R F E^{\mathrm{WT}}$ ratios. Percent variations of ratios are indicated (right) as medians and IQR (25 to 75\%). Mann-Whitney test for $P$ values. (C) Overall survival according to $E R F E^{+12} / E R F E^{+12}+$ ERFE ${ }^{\mathrm{WT}}$ ratio shown as a Kaplan-Meier curve. A threshold of positivity of 0.008 was determined by ROC analysis. Log-rank test for $P$ value. $\mathrm{ns}$, not significant.

apoptosis in terminal phases of differentiation $(1,2)$. Increased EPO and sTfR concentrations have been inversely correlated with hepcidin concentrations in $\operatorname{MDS}(17,18,41,42)$. Our study indicates that plasma hepcidin concentration in $S F 3 B 1^{\mathrm{MUT}}$ MDS is similar to healthy non-blood donor controls and inappropriately low compared to $S F 3 B 1^{\text {WT }}$ MDS, suggesting that its production could be dysregulated by severe ineffective erythropoiesis and/or a more specific mechanism (17). We showed the cell-autonomous $S F 3 B 1^{\mathrm{MUT}}$-dependent expression of $E R F E^{+12}$ and a role for increased concentrations of circulating ERFE in hepcidin reduction. This confirms the involvement of ERFE in human pathologies (27).

ERFE is the major erythroid regulator of hepcidin (26). Other candidate regulators of hepcidin linked to erythropoiesis have been proposed, including EPO and GDF-15. Although EPO administration decreases hepcidin concentration (43), this effect is predominantly indirect. The other candidate, GDF-15, is poorly induced by EPO in human volunteers. Although serum GDF-15 concentration was increased in $\beta$-thalassemia or congenital dyserythropoietic anemia, it was not inversely correlated with hepcidin in $\operatorname{MDS}(17,24,44)$. Low hepcidin preserves ferroportin on enterocytes and macrophages, causing increased intestinal absorption and macrophage release of iron $(45,46)$. Compared to $S F 3 B 1^{\text {WT }}$ MDS, the lower concentrations of hepcidin in $S F 3 B 1^{\mathrm{MUT}}$ MDS may explain early iron overload before patients receive erythrocyte transfusions $(17,18)$. In patients with low transfusion burden, who had received a mean of 0.5 RBC units, hepcidin, ERFE, and $S F 3 B 1$ mutation were independent predictors of hyperferritinemia. This demonstrates that iron overload is strongly related to the control of hepcidin through the SF3B1-regulated production of ERFE. Hepcidin increases with transfusion intensity in patients with MDS or $\beta$-thalassemia because of exogenous iron loading and transient suppression of ineffective erythropoiesis $(27,47,48)$. Here, in regularly transfused patients with $S F 3 B 1^{\text {MUT }}$ MDS, hepcidin remained lower and ERFE remained higher than in patients with $S F 3 B 1^{\mathrm{WT}}$ MDS. This establishes a driver role for SF3B1 mutation in the stimulation of ERFE expression and systemic iron overload that characterized patients.

The SF3B1 mutation confers a good prognosis in MDS $(6,49)$. However, when patients are transfusion dependent, iron overload in cardiac and liver tissues becomes clinically evident and may impair life expectancy (50). Chelation efficiently reduces iron burden in regularly transfused patients with MDS and serves as an adjuvant therapy for anemia, because deferasirox may improve hematopoiesis by protecting against oxidative stress (51-53). Promising substitutes for ESAs in resistant patients include lenalidomide, which may transiently reduce $S F 3 B 1$ mutant allele burden, and activin receptor ligand traps such as luspatercept, which promotes late-stage erythropoiesis in mouse models of $\beta$-thalassemia and MDS and diminishes iron overload in $\beta$-thalassemia mice $(33,54-56)$. In lenalidomide-treated patients, but not in epoetin $\zeta$-treated patients, 
the kinetics of $E R F E^{+12}$ expression correlated with the response to treatment, indicating that in responding patients, lenalidomide targeted clonal erythroid precursors either directly or indirectly. Changes in plasma ERFE protein after lenalidomide were not correlated with the response to these treatments. The impact of transfusions on the regulation of ERFE expression at the post-transcriptional level should be examined in the future. $E R F E^{+12}$ expression could also be useful for disease surveillance of patients with MDS-RS treated with other drugs, such as luspatercept. Further clinical studies will be required to validate $E R F E^{+12}$ expression as a therapy-responsive biomarker of ineffective erythropoiesis in patients with SF3B $1^{\text {MUT }}$ MDS.

Last, our findings open therapeutic avenues for preventing iron accumulation in patients with MDS-RS. Increasing hepcidin could produce therapeutic benefits in $S F 3 B 1^{\mathrm{MUT}}$ MDS, because a moderate increase in hepcidin decreased iron and improved anemia in $\beta$-thalassemia mice (57). Therefore, either the administration of a hepcidin agonist or the targeting of ERFE overexpression may provide a potential strategy for preventing iron overload and improving erythropoiesis in patients with SF3B1 $1^{\text {MUT }}$ MDS.

\section{MATERIALS AND METHODS \\ Study design}

The study involved identifying a splicing variant of ERFE by RNAsequencing human primary BM samples and the variant peptide by mass spectrometry. Each in vitro experiment (transfection, minigene assay, Degron-KI, transcriptional repression of hepcidin) was repeated three times. Each experiment using primary cells was performed with at least three samples in each category. A ratio of ERFE variant transcript to total transcript was validated as a marker of clonal erythropoiesis on the basis of the response to lenalidomide or ESA in two cohorts of patients with MDS enrolled in clinical trials and as a prognostic marker of OS in a prospective multicenter cohort of patients with MDS. Predictive value of plasma ERFE and hepcidin concentrations for hyperferritinemia was measured in training and validation cohorts of patients with MDS. For these studies, randomization or blinding was not applicable.

\section{Patients}

For the training cohort, patients with MDS $(n=156)$ were enrolled between 2008 and 2017 (ClinicalTrials.gov: GFM-LenEpo-2008, NCT01718379; GFM-Retacrit-2013, NCT 03598582). For the GFM-Retacrit-2013 cohort, the status of response to epoetin $\zeta$ was recorded. The prospective cohort of 90 patients with MDS with survival data was enrolled between 2010 and 2018. BM aspirates and PB plasma samples were collected after each patient gave informed consent for biological investigations according to the recommendations of the institutional review boards (IRBs): IdF X GFM-LenEpo-08 EudraCT 2008-008262-12, IdFII 2010-A00033-36, IdFIII 2010-2753, IdFV 212-A01395-38 EudraCT 2012-002990-7338, and OncoCCH 2015$08-11$-DC. For the validation cohort, patients with MDS $(n=55)$ were enrolled prospectively for plasma collection in France (five centers; IRB Onco-CCH 2015-08-11 DC) and Germany (one center; IRB Ethikkommission an der TU Dresden; EK 115032015) between 2016 and 2018. BM samples from five age-matched controls and PB plasma samples from 20 healthy controls were collected. Patient characteristics are indicated in tables S1, S5, and S7 and according to the response to epoetin $\zeta$ in table S6. Low transfusion burden was defined as $<4$ RBC units per 8 weeks.

\section{DNA and RNA sequencing}

Mutations in a panel of 26 genes were screened by next-generation sequencing (NGS) (fig. S1). RNA was sequenced on an Illumina HiSeq 2500 platform using a 100-base pair paired-end sequencing strategy. TopHat (v2.0.6) was used to align the reads against the human reference genome Hg19 RefSeq (RNA sequences, GRCh37) downloaded from the University of California, Santa Cruz Genome Browser (http://genome.ucsc.edu). Analyses of differential gene expression and differential junction read counts were performed using DESeq2 $(13,28)$.

\section{CRISPR-Cas9 generation of isogenic $S f 3 b 1^{\mathrm{K} 700 \mathrm{E}}$ and $S f 3 b 1^{\mathrm{WT}}$ cell lines}

The murine erythroid cell line G1E-ER4 (58) was used to generate isogenic $S f 3 b 1^{\mathrm{K} 700 \mathrm{E}}$ and $S f 3 b 1^{\mathrm{WT}}$ cell lines using CRISPR-Cas9stimulated homology-mediated repair.

\section{ERFE and ENOSF 1 minigenes}

The ERFE minigene was synthesized by insertion of the ERFE alternative junction in pET01 Exontrap vector (MoBiTec). G1E-ER4 9.2 $\left(S F 3 B 1^{\mathrm{WT}}\right)$ and G1E-ER4 5.13H $\left(S F 3 B 1^{\mathrm{K} 700 \mathrm{E}}\right)$ cells were transfected and processed for fluorescent PCR.

\section{Mass spectrometry analysis}

Erythroblasts were lysed, and peptides were obtained by trypsin digestion (Promega) and analyzed by nano liquid chromatography coupled with a Q Exactive Plus mass spectrometer (Thermo Fisher Scientific). Data were analyzed using Mascot 2.5.1 (www.matrixscience.com).

\section{Human ERFE quantification}

Plasma ERFE concentration was determined as previously described (27).

\section{Statistical analysis}

For quantitative variables, values were compared using the MannWhitney test. Categorical variables were compared using $\chi^{2}$ or Fisher's exact tests. $P$ values $<0.05$ were considered significant. ROC analysis was used to calculate the thresholds of positivity. Multivariate logistic regression analysis was adjusted for selected variables chosen with $P<0.1$ in univariate analysis (JMP version 10.0.2, SAS Institute Inc.).

\section{SUPPLEMENTARY MATERIALS}

stm.sciencemag.org/cgi/content/full/11/500/eaav5467/DC1

Materials and Methods

Fig. S1. Genomic characteristics of the training cohort of 156 patients with MDS

Fig. S2. Identification of in-frame alternative transcripts in $S F 3 B 1^{\mathrm{MUT}}$ MDS samples by RNA sequencing.

Fig. S3. Allele-specific investigation of mutant SF3B1 causal relationship to aberrantly spliced $E R F E^{+12}$ transcript using Degron-KI strategy.

Fig. S4. Massive use of FAM132B/ERFE cryptic junction in one MDS-RS with a bi-allelic alteration of the SF3B1 gene.

Fig. S5. Identification of ERFE peptide by LC MS/MS

Fig. S6. Correlation of plasma ERFE concentrations with ERFE ${ }^{+12}$ transcript, WHO classification, and iron homeostasis parameters.

Fig. S7. Biological parameters of low transfusion burden patients with MDS in the training cohort.

Fig. S8. Plasma ERFE, ferritin, and hepcidin concentrations at enrollment in 59 patients with MDS according to the response to EPO.

Fig. S9. Erythroid-specific expression of ERFE variant transcript.

Fig. S10. Variations of ERFE ${ }^{+12}$ transcript expression $S F 3 B 1^{\text {MUT }}$ low-risk MDS after therapy

Fig. S11. Variations in plasma concentration of ERFE protein in $S F 3 B 1^{\mathrm{MUT}}$ low-risk MDS after therapy.

Fig. S12. Kaplan-Meier curve for the analysis of OS according to $E R F E^{+12} / E R F E^{\mathrm{WT}}+E R F E^{+12}$ ratio. 
Table S1. Clinical and biological characteristics of the training cohort of 156 patients with MDS according to SF3B1 status.

Table S2. Differential expression of ERFE transcripts according to the mutational status of $S F 3 B 1, T E T 2$, and DNMT3A genes by RNA sequencing.

Table S3. Primer sequences used for fluorescent PCR and RT-qPCR.

Table S4. Expression of total ERFE, ERFE ${ }^{\mathrm{WT}}$, and $E R F E^{+12}$ transcripts by fluorescent PCR and RT-qPCR in nine MDS BM samples.

Table S5. Clinical and biological characteristics of the validation cohort of 55 patients with MDS according to SF3B1 status.

Table S6. Clinical and biological characteristics of the cohort of 59 patients with MDS in the GFM-Retacrit-2013 cohort according to response status.

Table S7. Clinical and biological characteristics of the cohort of 90 patients with MDS with survival data according to SF3B1 and ERFE ${ }^{+12}$ status.

Data file S1. Differentially expressed transcripts between patients with $S F 3 B 1^{\text {MUT }}$ and $S F 3 B 1^{\text {WT }}$ MDS by RNA sequencing and custom code.

Data file S2. Differentially expressed $5^{\prime}$ and $3^{\prime}$ junctions between patients with $S F 3 B 1^{\text {MUT }}$ and SF $3 B 1^{\text {WT }}$ MDS by RNA sequencing.

Data file S3. In-frame and differentially expressed $3^{\prime}$ cryptic ss junctions in $S F 3 B 1^{\mathrm{MUT}}$ MDS References $(59,60)$

\section{REFERENCES AND NOTES}

1. R. Tehranchi, R. Invernizzi, A. Grandien, B. Zhivotovsky, B. Fadeel, A.-M. Forsblom, E. Travaglino, J. Samuelsson, R. Hast, L. Nilsson, M. Cazzola, R. Wibom, E. Hellström-Lindberg, Aberrant mitochondrial iron distribution and maturation arrest characterize early erythroid precursors in low-risk myelodysplastic syndromes. Blood 106, 247-253 (2005).

2. E. Gyan, E. Frisan, O. Beyne-Rauzy, J.-C. Deschemin, C. Pierre-Eugene, C. Randriamampita, A. Dubart-Kupperschmitt, C. Garrido, F. Dreyfus, P. Mayeux, C. Lacombe, E. Solary, M. Fontenay, Spontaneous and Fas-induced apoptosis of low-grade MDS erythroid precursors involves the endoplasmic reticulum. Leukemia 22, 1864-1873 (2008).

3. Y. Zhu, X. Li, C. Chang, F. Xu, Q. He, J. Guo, Y. Tao, Y. Liu, L. Liu, W. Shi, SF3B1-mutated myelodysplastic syndrome with ring sideroblasts harbors more severe iron overload and corresponding over-erythropoiesis. Leuk. Res. 44, 8-16 (2016).

4. L. de Swart, C. Reiniers, T. Bagguley, C. van Marrewijk, D. Bowen, E. Hellström-Lindberg, A. Tatic, A. Symeonidis, G. Huls, J. Cermak, A. A. van de Loosdrecht, H. Garelius, D. Culligan, M. Macheta, M. Spanoudakis, P. Panagiotidis, M. Krejci, N. Blijlevens, S. Langemeijer, J. Droste, D. W. Swinkels, A. Smith, T. de Witte; EUMDS Steering Committee, Labile plasma iron levels predict survival in patients with lower-risk myelodysplastic syndromes. Haematologica 103, 69-79 (2018)

5. K. Yoshida, M. Sanada, Y. Shiraishi, D. Nowak, Y. Nagata, R. Yamamoto, Y. Sato, A. Sato-Otsubo, A. Kon, M. Nagasaki, G. Chalkidis, Y. Suzuki, M. Shiosaka, R. Kawahata, T. Yamaguchi, M. Otsu, N. Obara, M. Sakata-Yanagimoto, K. Ishiyama, H. Mori, F. Nolte, W.-K. Hofmann, S. Miyawaki, S. Sugano, C. Haferlach, H. P. Koeffler, L.-Y. Shih, T. Haferlach, S. Chiba, H. Nakauchi, S. Miyano, S. Ogawa, Frequent pathway mutations of splicing machinery in myelodysplasia. Nature 478, 64-69 (2011).

6. E. Papaemmanuil, M. Cazzola, J. Boultwood, L. Malcovati, P. Vyas, D. Bowen, A. Pellagatti, J. S. Wainscoat, E. Hellstrom-Lindberg, C. Gambacorti-Passerini, A. L. Godfrey, I. Rapado, A. Cvejic, R. Rance, C. McGee, P. Ellis, L. J. Mudie, P. J. Stephens, S. McLaren, C. E. Massie, P. S. Tarpey, I. Varela, S. Nik-Zainal, H. R. Davies, A. Shlien, D. Jones, K. Raine, J. Hinton, A. P. Butler, J. W. Teague, E. J. Baxter, J. Score, A. Galli, M. G. Della Porta, E. Travaglino, M. Groves, S. Tauro, N. C. Munshi, K. C. Anderson, A. El-Naggar, A. Fischer, V. Mustonen, A. J. Warren, N. C. P. Cross, A. R. Green, P. A. Futreal, M. R. Stratton, P. J. Campbell; Chronic Myeloid Disorders Working Group of the International Cancer Genome Consortium, Somatic SF3B1 mutation in myelodysplasia with ring sideroblasts. N. Engl. J. Med. 365, 1384-1395 (2011).

7. F. Damm, O. Kosmider, V. Gelsi-Boyer, A. Renneville, N. Carbuccia, C. Hidalgo-Curtis, V. Della Valle, L. Couronné, L. Scourzic, V. Chesnais, A. Guerci-Bresler, B. Slama, O. Beyne-Rauzy, A. Schmidt-Tanguy, A. Stamatoullas-Bastard, F. Dreyfus, T. Prébet, S. de Botton, N. Vey, M. A. Morgan, N. C. P. Cross, C. Preudhomme, D. Birnbaum, O. A. Bernard, M. Fontenay; Groupe Francophone des Myélodysplasies, Mutations affecting mRNA splicing define distinct clinical phenotypes and correlate with patient outcome in myelodysplastic syndromes. Blood 119, 3211-3218 (2012).

8. S. A. Mian, K. Rouault-Pierre, A. E. Smith, T. Seidl, I. Pizzitola, A. Kizilors, A. G. Kulasekararaj, D. Bonnet, G. J. Mufti, SF3B1 mutant MDS-initiating cells may arise from the haematopoietic stem cell compartment. Nat. Commun. 6, 10004 (2015).

9. V. Chesnais, M.-L. Arcangeli, C. Delette, A. Rousseau, H. Guermouche, C. Lefevre, S. Bondu, M. Diop, M. Cheok, N. Chapuis, L. Legros, S. Raynaud, L. Willems, D. Bouscary, E. Lauret, O. A. Bernard, O. Kosmider, F. Pflumio, M. Fontenay, Architectural and functional heterogeneity of hematopoietic stem/progenitor cells in non-del(5q) myelodysplastic syndromes. Blood 129, 484-496 (2017).
10. T. Mortera-Blanco, M. Dimitriou, P. S. Woll, M. Karimi, E. Elvarsdottir, S. Conte, M. Tobiasson, M. Jansson, I. Douagi, M. Moarii, L. Saft, E. Papaemmanuil, S. E. W. Jacobsen, E. Hellström-Lindberg, SF3B1-initiating mutations in MDS-RSs target lymphomyeloid hematopoietic stem cells. Blood 130, 881-890 (2017).

11. R. B. Darman, M. Seiler, A. A. Agrawal, K. H. Lim, S. Peng, D. Aird, S. L. Bailey, E. B. Bhavsar, B. Chan, S. Colla, L. Corson, J. Feala, P. Fekkes, K. Ichikawa, G. F. Keaney, L. Lee, P. Kumar, K. Kunii, C. MacKenzie, M. Matijevic, Y. Mizui, K. Myint, E. S. Park, X. Puyang, A. Selvaraj, M. P. Thomas, J. Tsai, J. Y. Wang, M. Warmuth, H. Yang, P. Zhu, G. Garcia-Manero, R. R. Furman, L. Yu, P. G. Smith, S. Buonamici, Cancer-associated SF3B1 hotspot mutations induce cryptic 3' splice site selection through use of a different branch point. Cell Rep. 13, 1033-1045 (2015).

12. E. A. Obeng, R. J. Chappell, M. Seiler, M. C. Chen, D. R. Campagna, P. J. Schmidt, R. K. Schneider, A. M. Lord, L. Wang, R. G. Gambe, M. E. McConkey, A. M. Ali, A. Raza, L. Yu, S. Buonamici, P. G. Smith, A. Mullally, C. J. Wu, M. D. Fleming, B. L. Ebert, Physiologic expression of $\mathrm{Sf} 3 \mathrm{~b} 1(\mathrm{~K} 700 \mathrm{E})$ causes impaired erythropoiesis, aberrant splicing, and sensitivity to therapeutic spliceosome modulation. Cancer Cell 30, 404-417 (2016).

13. S. Alsafadi, A. Houy, A. Battistella, T. Popova, M. Wassef, E. Henry, F. Tirode, A. Constantinou, S. Piperno-Neumann, S. Roman-Roman, M. Dutertre, M.-H. Stern, Cancer-associated SF3B1 mutations affect alternative splicing by promoting alternative branchpoint usage. Nat. Commun. 7, 10615 (2016).

14. L. Wang, A. N. Brooks, J. Fan, Y. Wan, R. Gambe, S. Li, S. Hergert, S. Yin, S. S. Freeman, J. Z. Levin, L. Fan, M. Seiler, S. Buonamici, P. G. Smith, K. F. Chau, C. L. Cibulskis, W. Zhang, L. Z. Rassenti, E. M. Ghia, T. J. Kipps, S. Fernandes, D. B. Bloch, D. Kotliar, D. A. Landau, S. A. Shukla, J. C. Aster, R. Reed, D. S. DeLuca, J. R. Brown, D. Neuberg, G. Getz, K. J. Livak, M. M. Meyerson, P. V. Kharchenko, C. J. Wu, Transcriptomic characterization of SF3B1 mutation reveals its pleiotropic effects in chronic lymphocytic leukemia. Cancer Cell 30, 750-763 (2016).

15. A. Pellagatti, R. N. Armstrong, V. Steeples, E. Sharma, E. Repapi, S. Singh, A. Sanchi, A. Radujkovic, P. Horn, H. Dolatshad, S. Roy, J. Broxholme, H. Lockstone, S. Taylor, A. Giagounidis, P. Vyas, A. Schuh, A. Hamblin, E. Papaemmanuil, S. Killick, L. Malcovati, M. L. Hennrich, A. C. Gavin, A. D. Ho, T. Luft, E. Hellström-Lindberg, M. Cazzola, C. W. J. Smith, S. Smith, J. Boultwood, Impact of spliceosome mutations on RNA splicing in myelodysplasia: Dysregulated genes/pathways and clinical associations. Blood 132, 1225-1240 (2018).

16. Y. Shiozawa, L. Malcovati, A. Galli, A. Sato-Otsubo, K. Kataoka, Y. Sato, Y. Watatani, H. Suzuki, T. Yoshizato, K. Yoshida, M. Sanada, H. Makishima, Y. Shiraishi, K. Chiba, E. Hellström-Lindberg, S. Miyano, S. Ogawa, M. Cazzola, Aberrant splicing and defective mRNA production induced by somatic spliceosome mutations in myelodysplasia. Nat. Commun. 9, 3649 (2018).

17. V. Santini, D. Girelli, A. Sanna, N. Martinelli, L. Duca, N. Campostrini, A. Cortelezzi, M. Corbella, A. Bosi, G. Reda, O. Olivieri, M. D. Cappellini, Hepcidin levels and their determinants in different types of myelodysplastic syndromes. PLOS ONE 6, e23109 (2011)

18. I. Ambaglio, L. Malcovati, E. Papaemmanuil, C. M. Laarakkers, M. G. D. Porta, A. Galli, M. C. D. Vià, E. Bono, M. Ubezio, E. Travaglino, R. Albertini, P. J. Campbell, D. W. Swinkels, M. Cazzola, Inappropriately low hepcidin levels in patients with myelodysplastic syndrome carrying a somatic mutation of SF3B1. Haematologica 98, 420-423 (2013).

19. D. A. Weinstein, C. N. Roy, M. D. Fleming, M. F. Loda, J. I. Wolfsdorf, N. C. Andrews, Inappropriate expression of hepcidin is associated with iron refractory anemia: Implications for the anemia of chronic disease. Blood 100, 3776-3781 (2002).

20. G. Nicolas, C. Chauvet, L. Viatte, J. L. Danan, X. Bigard, I. Devaux, C. Beaumont, A. Kahn, S. Vaulont, The gene encoding the iron regulatory peptide hepcidin is regulated by anemia, hypoxia, and inflammation. J. Clin. Invest. 110, 1037-1044 (2002).

21. E. Nemeth, E. V. Valore, M. Territo, G. Schiller, A. Lichtenstein, T. Ganz, Hepcidin, a putative mediator of anemia of inflammation, is a type II acute-phase protein. Blood 101, 2461-2463 (2003).

22. M. Pak, M. A. Lopez, V. Gabayan, T. Ganz, S. Rivera, Suppression of hepcidin during anemia requires erythropoietic activity. Blood 108, 3730-3735 (2006).

23. L. Malcovati, E. Papaemmanuil, D. T. Bowen, J. Boultwood, M. G. D. Porta, C. Pascutto, E. Travaglino, M. J. Groves, A. L. Godfrey, I. Ambaglio, A. Gallì, M. C. D. Vià, S. Conte, S. Tauro, N. Keenan, A. Hyslop, J. Hinton, L. J. Mudie, J. S. Wainscoat, P. A. Futreal, M. R. Stratton, P. J. Campbell, E. Hellström-Lindberg, M. Cazzola; Chronic Myeloid Disorders Working Group of the International Cancer Genome Consortium and of the Associazione Italiana per la Ricerca sul Cancro Gruppo Italiano Malattie Mieloproliferative, Clinical significance of SF3B1 mutations in myelodysplastic syndromes and myelodysplastic/myeloproliferative neoplasms. Blood 118, 6239-6246 (2011).

24. T. Tanno, N. V. Bhanu, P. A. Oneal, S.-H. Goh, P. Staker, Y. T. Lee, J. W. Moroney, C. H. Reed, N. L. C. Luban, R.-H. Wang, T. E. Eling, R. Childs, T. Ganz, S. F. Leitman, S. Fucharoen, J. L. Miller, High levels of GDF15 in thalassemia suppress expression of the iron regulatory protein hepcidin. Nat. Med. 13, 1096-1101 (2007).

25. T. Tanno, P. Porayette, O. Sripichai, S.-J. Noh, C. Byrnes, A. Bhupatiraju, Y. T. Lee, J. B. Goodnough, O. Harandi, T. Ganz, R. F. Paulson, J. L. Miller, Identification of TWSG 
as a second novel erythroid regulator of hepcidin expression in murine and human cells. Blood 114, 181-186 (2009).

26. L. Kautz, G. Jung, E. V. Valore, S. Rivella, E. Nemeth, T. Ganz, Identification of erythroferrone as an erythroid regulator of iron metabolism. Nat. Genet. 46, 678-684 (2014).

27. T. Ganz, G. Jung, A. Naeim, Y. Ginzburg, Z. Pakbaz, P. B. Walter, L. Kautz, E. Nemeth, Immunoassay for human serum erythroferrone. Blood 130, 1243-1246 (2017).

28. M. I. Love, W. Huber, S. Anders, Moderated estimation of fold change and dispersion for RNA-seq data with DESeq2. Genome Biol. 15, 550 (2014).

29. Q. Zhou, A. Derti, D. Ruddy, D. Rakiec, I. Kao, M. Lira, V. Gibaja, H. Chan, Y. Yang, J. Min, M. R. Schlabach, F. Stegmeier, A chemical genetics approach for the functional assessment of novel cancer genes. Cancer Res. 75, 1949-1958 (2015).

30. S. Park, O. Kosmider, F. Maloisel, B. Drenou, N. Chapuis, T. Lefebvre, Z. Karim, H. Puy, A. S. Alary, S. Ducamp, F. Verdier, C. Bouilloux, A. Rousseau, M.-C. Jacob, A. Debliquis, A. Charpentier, E. Gyan, B. Anglaret, C. Leyronnas, S. Corm, B. Slama, S. Cheze, K. Laribi, S. Amé, C. Rose, F. Lachenal, A. Toma, G. M. Pica, M. Carre, F. Garban, C. Mariette, J.-Y. Cahn, M. Meunier, O. Herault, P. Fenaux, O. Wagner-Ballon, V. Bardet, F. Dreyfus, M. Fontenay, Dyserythropoiesis evaluated by the RED score and hepcidin:ferritin ratio predicts response to erythropoietin in lower-risk myelodysplastic syndromes. Haematologica 104, 497-504 (2019).

31. F. Damm, E. Mylonas, A. Cosson, K. Yoshida, V. D. Valle, E. Mouly, M. Diop, L. Scourzic, Y. Shiraishi, K. Chiba, H. Tanaka, S. Miyano, Y. Kikushige, F. Davi, J. Lambert, D. Gautheret, H. Merle-Béral, L. Sutton, P. Dessen, E. Solary, K. Akashi, W. Vainchenker, T. Mercher, N. Droin, S. Ogawa, F. Nguyen-Khac, O. A. Bernard, Acquired initiating mutations in early hematopoietic cells of CLL patients. Cancer Discov. 4, 1088-1101 (2014).

32. H. Dolatshad, A. Pellagatti, F. G. Liberante, M. Llorian, E. Repapi, V. Steeples, S. Roy, L. Scifo, R. N. Armstrong, J. Shaw, B. H. Yip, S. Killick, R. Kušec, S. Taylor, K. I. Mills, K. I. Savage, C. W. J. Smith, J. Boultwood, Cryptic splicing events in the iron transporter $A B C B 7$ and other key target genes in SF3B1-mutant myelodysplastic syndromes. Leukemia 30, 2322-2331 (2016).

33. V. Chesnais, A. Renneville, A. Toma, J. Lambert, M. Passet, F. Dumont, S. Chevret, J. Lejeune, A. Raimbault, A. Stamatoullas, C. Rose, O. Beyne-Rauzy, J. Delaunay, E. Solary, P. Fenaux, F. Dreyfus, C. Preudhomme, O. Kosmider, M. Fontenay; Groupe Francophone des Myélodysplasies, Effect of lenalidomide treatment on clonal architecture of myelodysplastic syndromes without 5q deletion. Blood 127, 749-760 (2016).

34. A. Toma, O. Kosmider, S. Chevret, J. Delaunay, A. Stamatoullas, C. Rose, O. Beyne-Rauzy, A. Banos, A. Guerci-Bresler, S. Wickenhauser, D. Caillot, K. Laribi, B. De Renzis, D. Bordessoule, C. Gardin, B. Slama, L. Sanhes, B. Gruson, P. Cony-Makhoul, B. Chouffi, C. Salanoubat, R. Benramdane, L. Legros, E. Wattel, G. Tertian, K. Bouabdallah, F. Guilhot, A. L. Taksin, S. Cheze, K. Maloum, S. Nimuboma, C. Soussain, F. Isnard, E. Gyan, R. Petit, J. Lejeune, V. Sardnal, A. Renneville, C. Preudhomme, M. Fontenay, P. Fenaux, F. Dreyfus, Lenalidomide with or without erythropoietin in transfusion-dependent erythropoiesis-stimulating agent-refractory lower-risk MDS without 5q deletion. Leukemia 30, 897-905 (2016).

35. Y. Shiozawa, S. Sato-Otsubo, A. Galli, K. Yoshida, T. Yoshizato, Y. Sato, K. Kataoka, M. Sanada, Y. Shiraishi, K. Chiba, S. Miyano, L. Malcovati, M. Cazzola, S. Ogawa, Comprehensive analysis of aberrant RNA splicing in myelodysplastic syndromes. Blood 124, 826 (2014).

36. C. Cretu, J. Schmitzová, A. Ponce-Salvatierra, O. Dybkov, E. I. De Laurentiis, K. Sharma, C. L. Will, H. Urlaub, R. Lührmann, V. Pena, Molecular architecture of SF $3 b$ and structural consequences of its cancer-related mutations. Mol. Cell 64, 307-319 (2016).

37. M. Nikpour, C. Scharenberg, A. Liu, S. Conte, M. Karimi, T. Mortera-Blanco, V. Giai, M. Fernandez-Mercado, E. Papaemmanuil, K. Högstrand, M. Jansson, I. Vedin, J. Stephen Wainscoat, P. Campbell, M. Cazzola, J. Boultwood, A. Grandien, E. Hellström-Lindberg, The transporter $A B C B 7$ is a mediator of the phenotype of acquired refractory anemia with ring sideroblasts. Leukemia 27, 889-896 (2013).

38. V. Quesada, L. Conde, N. Villamor, G. R. Ordóñez, P. Jares, L. Bassaganyas, A. J. Ramsay, S. Beà, M. Pinyol, A. Martínez-Trillos, M. López-Guerra, D. Colomer, A. Navarro, T. Baumann, M. Aymerich, M. Rozman, J. Delgado, E. Giné, J. M. Hernández, M. González-Díaz, D. A. Puente, G. Velasco, J. M. P. Freije, J. M. C. Tubío, R. Royo, J. L. Gelpí, M. Orozco, D. G. Pisano, J. Zamora, M. Vázquez, A. Valencia, H. Himmelbauer, M. Bayés, S. Heath, M. Gut, I. Gut, X. Estivill, A. López-Guillermo, X. S. Puente, E. Campo, C. López-Otín, Exome sequencing identifies recurrent mutations of the splicing factor SF3B1 gene in chronic lymphocytic leukemia. Nat. Genet. 44, 47-52 (2011).

39. D. Gentien, O. Kosmider, F. Nguyen-Khac, B. Albaud, A. Rapinat, A. G. Dumont, F. Damm, T. Popova, R. Marais, M. Fontenay, S. Roman-Roman, O. A. Bernard, M.-H. Stern, A common alternative splicing signature is associated with SF3B1 mutations in malignancies from different cell lineages. Leukemia 28, 1355-1357 (2014).

40. M. M. Seldin, S. Y. Tan, G. W. Wong, Metabolic function of the CTRP family of hormones. Rev. Endocr. Metab. Disord. 15, 111-123 (2014).

41. S. J. L. Brada, J. T. de Wolf, D. Hendriks, H. Louwes, E. van den Berg, E. Vellenga, Characterization of the erythropoiesis in myelodysplasia by means of ferrokinetic studies, in vitro erythroid colony formation and soluble transferrin receptor. Leukemia 12, 340-345 (1998).
42. G. Metzgeroth, P. L. Rosée, C. Kuhn, B. Schultheis, A. Dorn-Beineke, R. Hehlmann, J. Hastka, The soluble transferrin receptor in dysplastic erythropoiesis in myelodysplastic syndrome. Eur. J. Haematol. 79, 8-16 (2007).

43. D. R. Ashby, D. P. Gale, M. Busbridge, K. G. Murphy, N. D. Duncan, T. D. Cairns, D. H. Taube, S. R. Bloom, F. W. K. Tam, R. Chapman, P. H. Maxwell, P. Choi, Erythropoietin administration in humans causes a marked and prolonged reduction in circulating hepcidin. Haematologica 95, 505-508 (2010).

44. H. Tamary, H. Shalev, G. Perez-Avraham, M. Zoldan, I. Levi, D. W. Swinkels, T. Tanno, J. L. Miller, Elevated growth differentiation factor 15 expression in patients with congenital dyserythropoietic anemia type I. Blood 112, 5241-5244 (2008).

45. G. Nicolas, L. Viatte, D.-Q. Lou, M. Bennoun, C. Beaumont, A. Kahn, N. C. Andrews, S. Vaulont, Constitutive hepcidin expression prevents iron overload in a mouse model of hemochromatosis. Nat. Genet. 34, 97-101 (2003).

46. E. Nemeth, M. S. Tuttle, J. Powelson, M. B. Vaughn, A. Donovan, D. M. Ward, T. Ganz, J. Kaplan, Hepcidin regulates cellular iron efflux by binding to ferroportin and inducing its internalization. Science 306, 2090-2093 (2004).

47. R. Cui, R. P. Gale, G. Zhu, Z. Xu, T. Qin, Y. Zhang, G. Huang, B. Li, L. Fang, H. Zhang, L. Pan, N. Hu, S. Qu, Z. Xiao, Serum iron metabolism and erythropoiesis in patients with myelodysplastic syndrome not receiving RBC transfusions. Leuk. Res. 38, 545-550 (2014).

48. S.-R. Pasricha, D. M. Frazer, D. K. Bowden, G. J. Anderson, Transfusion suppresses erythropoiesis and increases hepcidin in adult patients with $\beta$-thalassemia major: A longitudinal study. Blood 122, 124-133 (2013).

49. L. Malcovati, M. Karimi, E. Papaemmanuil, I. Ambaglio, M. Jädersten, M. Jansson, C. Elena, A. Galli, G. Walldin, M. G. Della Porta, K. Raaschou-Jensen, E. Travaglino, K. Kallenbach, D. Pietra, V. Ljungström, S. Conte, E. Boveri, R. Invernizzi, R. Rosenquist, P. J. Campbell, M. Cazzola, E. H. Lindberg, SF3B1 mutation identifies a distinct subset of myelodysplastic syndrome with ring sideroblasts. Blood 126, 233-241 (2015).

50. M. Cazzola, G. Barosi, P. G. Gobbi, R. Invernizzi, A. Riccardi, E. Ascari, Natural history of idiopathic refractory sideroblastic anemia. Blood 71, 305-312 (1988).

51. N. Gattermann, C. Finelli, M. D. Porta, P. Fenaux, M. Stadler, A. Guerci-Bresler, M. Schmid, K. Taylor, D. Vassilieff, D. Habr, A. Marcellari, B. Roubert, C. Rose, Hematologic responses to deferasirox therapy in transfusion-dependent patients with myelodysplastic syndromes. Haematologica 97, 1364-1371 (2012).

52. A. F. List, M. R. Baer, D. P. Steensma, A. Raza, J. Esposito, N. Martinez-Lopez, C. Paley, J. Feigert, E. Besa, Deferasirox reduces serum ferritin and labile plasma iron in RBC transfusion-dependent patients with myelodysplastic syndrome. J. Clin. Oncol. 30, 2134-2139 (2012).

53. M. Meunier, S. Ancelet, C. Lefebvre, J. Arnaud, C. Garrel, M. Pezet, Y. Wang, P. Faure, G. Szymanski, N. Duployez, C. Preudhomme, D. Biard, B. Polack, J.-Y. Cahn, J. M. Moulis, S. Park, Reactive oxygen species levels control NF-кB activation by low dose deferasirox in erythroid progenitors of low risk myelodysplastic syndromes. Oncotarget $\mathbf{8}$, 105510-105524 (2017).

54. U. Platzbecker, U. Germing, K. S. Götze, P. Kiewe, K. Mayer, J. Chromik, M. Radsak, T. Wolff, X. Zhang, A. Laadem, M. L. Sherman, K. M. Attie, A. Giagounidis, Luspatercept for the treatment of anaemia in patients with lower-risk myelodysplastic syndromes (PACE-MDS): A multicentre, open-label phase 2 dose-finding study with long-term extension study. Lancet Oncol. 18, 1338-1347 (2017).

55. R. N. V. S. Suragani, S. M. Cadena, S. M. Cawley, D. Sako, D. Mitchell, R. Li, M. V. Davies, M. J. Alexander, M. Devine, K. S. Loveday, K. W. Underwood, A. V. Grinberg, J. D. Quisel, R. Chopra, R. S. Pearsall, J. Seehra, R. Kumar, Transforming growth factor- $\beta$ superfamily ligand trap ACE-536 corrects anemia by promoting late-stage erythropoiesis. Nat. Med. 20, 408-414 (2014)

56. M. Dussiot, T. T. Maciel, A. Fricot, C. Chartier, O. Negre, J. Veiga, D. Grapton, E. Paubelle, E. Payen, Y. Beuzard, P. Leboulch, J.-A. Ribeil, J.-B. Arlet, F. Coté, G. Courtois, Y. Z. Ginzburg, T. O. Daniel, R. Chopra, V. Sung, O. Hermine, I. C. Moura, An activin receptor IIA ligand trap corrects ineffective erythropoiesis in $\beta$-thalassemia. Nat. Med. 20, 398-407 (2014).

57. S. Gardenghi, P. Ramos, M. F. Marongiu, L. Melchiori, L. Breda, E. Guy, K. Muirhead, N. Rao, C. N. Roy, N. C. Andrews, E. Nemeth, A. Follenzi, X. An, N. Mohandas, Y. Ginzburg, E. A. Rachmilewitz, P. J. Giardina, R. W. Grady, S. Rivella, Hepcidin as a therapeutic tool to limit iron overload and improve anemia in $\beta$-thalassemic mice. J. Clin. Invest. 120, 4466-4477 (2010).

58. J. J. Welch, J. A. Watts, C. R. Vakoc, Y. Yao, H. Wang, R. C. Hardison, G. A. Blobel, L. A. Chodosh, M. J. Weiss, Global regulation of erythroid gene expression by transcription factor GATA-1. Blood 104, 3136-3147 (2004).

59. P. Roepstorff, J. Fohlman, Proposal for a common nomenclature for sequence ions in mass spectra of peptides. Biomed. Mass Spectrom. 11, 601 (1984).

60. T. Lefebvre, N. Dessendier, D. Houamel, N. laly-Radio, C. Kannengiesser, H. Manceau, C. Beaumont, G. Nicolas, L. Gouya, H. Puy, Z. Karim, LC-MS/MS method for hepcidin-25 measurement in human and mouse serum: Clinical and research implications in iron disorders. Clin. Chem. Lab. Med. 53, 1557-1567 (2015). 
Acknowledgments: We thank F. Pflumio (INSERM UMR967, CEA/DSV/iRCM, Fontenay-aux-Roses), N. Taylor (Institut de Génétique Moléculaire, Montpellier), S. Vaulont (Institut Cochin), E.-F. Gautier (3P5 proteomic platform), J. Vinh (Ecole Supérieure de Physique et de Chimie Industrielles, Paris), B. Saint-Pierre (Institut Cochin), and D. Drubay (Institut Gustave Roussy) for fruitful discussions; S. Raynaud (Laboratoire d'oncohématologie, Hôpital Pasteur, Nice), J.-B. Arlet (Service de Médecine Interne, Hôpital Européen Pompidou Paris), and C. Kannengiesser (Service de Génétique, Hôpital Bichat Paris) for providing samples; F. Letourneur (Genom'IC, Institut Cochin), S. Baulande (sequencing platform, Institut Curie), L. Zaroili, M. Dejean, A. Marcon, V. Verjus-Lisfranc (Cochin Laboratory of Hematology), E. Benana (3P5 platform), and B. Billoré (INSERM U1220) for technical assistance; and M. Weiss (St Jude Children's Research Hospital, Memphis, TN) and V. Paralkar (University of Pennsylvania, Philadelphia, PA) for providing the G1E-ER4 cell line and expert comments. Funding: This study was funded by INSERM, by the Institut National du Cancer INCa PLBio 2015 (INCa_9290), by INCa and the Direction Générale de I'Offre de Soins (DGOS) of the French Ministry of Social Affairs and Health through the Programme Hospitalier de Recherche Clinique (PHRC MDS-04; INCa-DGOS_5480), and by the Site de Recherche Intégrée sur le Cancer (SIRIC) CAncer Research for PErsonalized Medicine (CARPEM). C.L. and D.R. are the recipients of a salary funded by the Laboratory of Excellence on red cells GR-Ex. The Orbitrap Fusion MS was acquired with funds from FEDER and "Canceropole lle de France." L.K. received support from ANR-16-ACHN-0002-01 and from the European Research Council (ERC) under the European Union's Horizon 2020 research and innovation program (grant agreement no. 715491). T.G. received funding from the NIH by R01 DK 065029 (and the UCLA Center for Accelerated Innovation, under NIH grant U54HL1 19893, Palazzolo). Author contributions: S.B., A-S.A., C.L., G.J., F.G., T.L., P.P., S.K., M.W., A.R., and L.K. performed the experiments and analyzed the data; A.R., S.W., and A.-S.K. recorded patient clinical data; A.H., D.R., A.B., N.C., and I.B. performed bioinformatics analyses; A.T., S.P., D.B., H.P., L.A., U.P., T.C., M.H., A.S., V.S., and E.G. provided samples; S.P. performed statistical analyses and reviewed the manuscript; F.G.,
N.D., S.A., Z.K., H.P., M.W., R.M., M-H.S., P.M., E.N., T.G., and L.K. analyzed the data and reviewed the manuscript; M.F. and O.K. designed the study, analyzed the data, and supervised the work; M.F. wrote the manuscript. Competing interests: T.G., L.K., and E.N. are inventors on a patent application on ERFE. T.G. and E.N. are scientific founders of Intrinsic LifeSciences and Silarus Pharma, companies that have interests related to ERFE. M.F., O.K., L.K., F.G., M.-H.S., S.A., and A.H. are inventors on a patent application on variant ERFE. The other authors declare that they have no competing interests. Data and materials availability: RNA-seq data are available in the Gene Expression Omnibus (GEO) repository (accession number GSE132836). Material transfer agreement with $\mathrm{H} 3$ Biomedicine Inc. (S. Buonamici) is required to obtain synthetic full-length $S F 3 B 1^{\mathrm{WT}}$ or mutant $S F 3 B 1^{\mathrm{K} 700 \mathrm{E}} \mathrm{CDNAs}$. The human erythroferrone assay is available from Intrinsic LifeSciences, La Jolla, CA. All other data associated with this study are present in the paper or the Supplementary Materials.

Submitted 27 September 2018

Resubmitted 19 March 2019

Accepted 12 June 2019

Published 10 July 2019

10.1126/scitransImed.aav5467

Citation: S. Bondu, A.-S. Alary, C. Lefèvre, A. Houy, G. Jung, T. Lefebvre, D. Rombaut, I. Boussaid, A. Bousta, F. Guillonneau, P. Perrier, S. Alsafadi, M. Wassef, R. Margueron, A. Rousseau, N. Droin, N. Cagnard, S. Kaltenbach, S. Winter, A.-S. Kubasch, D. Bouscary, V. Santini, A. Toma, M. Hunault, A. Stamatoullas, E. Gyan, T. Cluzeau, U. Platzbecker, L. Adès, H. Puy, M.-H. Stern, Z. Karim, P. Mayeux, E. Nemeth, S. Park, T. Ganz, L. Kautz, O. Kosmider, M. Fontenay, A variant erythroferrone disrupts iron homeostasis in SF3B1-mutated myelodysplastic syndrome. Sci. Transl. Med. 11, eaav5467 (2019). 


\section{Science Translational Medicine}

\section{A variant erythroferrone disrupts iron homeostasis in SF3B1-mutated myelodysplastic syndrome}

Sabrina Bondu, Anne-Sophie Alary, Carine Lefèvre, Alexandre Houy, Grace Jung, Thibaud Lefebvre, David Rombaut, Ismael Boussaid, Abderrahmane Bousta, François Guillonneau, Prunelle Perrier, Samar Alsafadi, Michel Wassef, Raphaël Margueron, Alice Rousseau, Nathalie Droin, Nicolas Cagnard, Sophie Kaltenbach, Susann Winter, Anne-Sophie Kubasch, Didier Bouscary, Valeria Santini, Andrea Toma, Mathilde Hunault, Aspasia Stamatoullas, Emmanuel Gyan, Thomas Cluzeau, Uwe Platzbecker, Lionel Adès, Hervé Puy, Marc-Henri Stern, Zoubida Karim, Patrick Mayeux, Elizabeta Nemeth, Sophie Park, Tomas Ganz, Léon Kautz, Olivier Kosmider and Michaëla Fontenay

Sci Transl Med 11, eaav5467.

DOI: 10.1126/scitransImed.aav5467

\section{Loading up on iron}

Myelodysplastic syndromes are clonal disorders of hematopoiesis with a variety of manifestations and potential complications. One category of myelodysplastic syndromes, those associated with ring sideroblasts, is known for causing iron overload even in the absence of transfusions, but the reasons for this are unclear. Bondu et al. discovered that a variant form of erythroferrone, a hormone that helps regulate bone marrow function, is produced in this disorder and results in deregulation of iron loading through suppression of the hormone hepcidin Moreover, the variant erythroferrone is not present in healthy bone marrow cells, indicating its potential utility as a biomarker of clonal hematopoiesis.

RELATED CONTENT

REFERENCES

PERMISSIONS

$$
\begin{aligned}
& \text { http://stm.sciencemag.org/content/scitransmed/10/436/eaan8292.full } \\
& \text { http://stm.sciencemag.org/content/scitransmed/10/429/eaam7729.full } \\
& \text { http://stm.sciencemag.org/content/scitransmed/9/374/eaaj2025.full } \\
& \text { http://stm.sciencemag.org/content/scitransmed/8/338/338ra67.full } \\
& \text { http://stm.sciencemag.org/content/scitransmed/11/506/eaav4881.full } \\
& \text { http://stke.sciencemag.org/content/sigtrans/12/598/eaap7336.full } \\
& \text { http://science.sciencemag.org/content/sci/368/6487/129.full } \\
& \text { http://science.sciencemag.org/content/sci/368/6487/186.full } \\
& \text { http://science.sciencemag.org/content/sci/369/6501/250.full } \\
& \text { http://science.sciencemag.org/content/sci/369/6501/276.full }
\end{aligned}
$$

This article cites 60 articles, 26 of which you can access for free http://stm.sciencemag.org/content/11/500/eaav5467\#BIBL

http://www.sciencemag.org/help/reprints-and-permissions

Use of this article is subject to the Terms of Service

Science Translational Medicine (ISSN 1946-6242) is published by the American Association for the Advancement of Science, 1200 New York Avenue NW, Washington, DC 20005. The title Science Translational Medicine is a registered trademark of AAAS.

Copyright @ 2019 The Authors, some rights reserved; exclusive licensee American Association for the Advancement of Science. No claim to original U.S. Government Works 